\title{
NANOFIBRAS ELETROFIADAS E SUAS APLICAÇÕES: AVANÇOS NA ÚLTIMA DÉCADA
}

\author{
Luiza A. Mercante, ${ }^{\mathrm{a}, *, \odot}$ Rafaela S. Andre $^{\mathrm{b}, \odot}$, Juliana B. Macedo $^{\mathrm{c}}$, Adriana Pavinatto ${ }^{\mathrm{c}, \odot}$ e Daniel S. Correa ${ }^{\mathrm{b}, \odot}$ \\ anstituto de Química, Universidade Federal da Bahia, 40170-115 Salvador - BA, Brasil \\ ${ }^{b}$ Laboratório Nacional de Nanotecnologia para o Agronegócio, Embrapa Instrumentação, 13560-970 São Carlos - SP, Brasil \\ 'Instituto Científico e Tecnológico, Universidade Brasil, 08230-030 São Paulo - SP, Brasil
}

Recebido em 26/09/2020; aceito em 05/01/2021; publicado na web em 18/02/2021

\begin{abstract}
ELECTROSPUN NANOFIBERS AND THEIR APPLICATIONS: ADVANCES IN THE LAST DECADE. In recent years there has been an increasing interest in the development of nanomaterials with improved properties compared to their counterparts at the micro- and macroscopic scale. In this context, nanofibers obtained by electrospinning technique are highly attractive due to the unique combination of high surface area/volume ratio, porosity, flexibility, mechanical performance, simple processing and relatively low cost. In addition, the possibility to buildup nanofibers with different compositions, structures and properties allows the design of nanostructures for a wide range of applications. In this review, we will discuss the advances of the last decade in the use of the electrospinning to obtain nanofibers with different compositions and morphologies for varied applications. Specifically, we are interested in providing an overview of the state of the art in relation to the application of nanofibers in different areas, including healthcare, environment, sensing and energy. Finally, we will discuss the real perspective in terms of industrial application and future trends that have been pursued to improve the performance of electrospun nanofibers. This review will help researchers to understand the evolution and challenges of the area and will also stimulate even more interest in the development of new devices based on electrospun nanofibers.
\end{abstract}

Keywords: nanotechnology; nanomaterials; nanofibers; electrospinning.

\section{INTRODUÇÃO}

As últimas décadas testemunharam um crescimento acentuado nas atividades relacionadas às áreas de Nanociência e Nanotecnologia, impulsionadas tanto pela necessidade de se entender os novos conceitos envolvidos quanto pelo potencial de aplicações e possíveis impactos na economia mundial, oferecendo soluções para desafios científicos, industriais e comerciais por meio do desenvolvimento e aplicação de nanomateriais com propriedades funcionais otimizadas..$^{1-3}$

Um nanomaterial pode ser definido como um material no qual pelo menos uma de suas dimensões $(d)$ é menor ou igual ao tamanho crítico $\left(d^{*}\right)$, satisfazendo assim a seguinte relação: $d \leq d^{*} \approx 100 \mathrm{~nm} \cdot{ }^{4-7}$ O valor de $d^{*}$ não possui um magnitude definida, pois depende dos parâmetros de alguns fenômenos físicos (comprimento de onda de de Broglie, comprimento de correlação, etc.) dando origem aos efeitos de tamanho dos materiais em nanoescala. ${ }^{4,7}$ Dessa forma, pode-se dizer que a correlação entre o tamanho crítico e a dimensão do nanomaterial é que irá determinar suas propriedades finais ou, mais especificamente, novos fenômenos e novas propriedades são esperados quando o tamanho do material se torna comparável ou igual ao tamanho crítico que governa a propriedade de interesse. ${ }^{4,7}$ Nos semicondutores, por exemplo, mudanças nas propriedades são observadas quando o material apresenta tamanho inferior ao raio de Bohr de éxciton, o que leva ao aparecimento de efeitos de confinamento quântico. ${ }^{8}$ Além disso, é importante ressaltar que as propriedades dos nanomateriais podem ser manipuladas variando-se tanto o tamanho crítico quanto a morfologia do mesmo.,

Os nanomateriais podem ser classificados em vários grupos com base em diferentes critérios. ${ }^{3,10,11}$ Geralmente, materiais na nanoescala podem ser categorizados de acordo com sua dimensionalidade, morfologia e/ou composição química. ${ }^{10,11} \mathrm{Com}$ base na dimensionalidade, por exemplo, as nanoestruturas podem

*e-mail: 1mercante@ufba.br ser classificadas em: (i) nanomateriais de dimensão zero $(O D)$ englobando pequenas partículas/aglomerados com as três dimensões restritas na nanoescala; (ii) nanomateriais unidimensionais (ID) envolvendo estruturas com duas dimensões em escala nanométrica e (iii) nanomateriais bidimensionais $(2 D)$ com apenas uma dimensão em escala nanométrica, como as nanofolhas, nanoplacas, filmes finos, entre outros. ${ }^{4,7,11,12}$

O design de nanoestruturas unidimensionais (1D) nas formas de tubos, fitas, fios, bastões e fibras tem despertado intenso interesse da comunidade científica nos últimos anos. ${ }^{12-14}$ Desde o advento da nanotecnologia, várias metodologias vêm sendo desenvolvidas para a geração de nanoestruturas $1 D$, desde técnicas altamente precisas, como nanolitografia ${ }^{15,16}$ e automontagem,,${ }^{17,18}$ até métodos que permitam a produção do material em larga escala. ${ }^{14}$ Dentro dessa última classe, destacam-se as várias tecnologias de fiação que resultam na preparação contínua e constante de materiais com diversas propriedades, dependendo da especificidade dos parâmetros e métodos adotados. ${ }^{19}$ Dentre as diferentes técnicas de fiação, a eletrofiação se evidencia como uma técnica de síntese versátil capaz de produzir fibras com uma larga variedade de composições, morfologias e diâmetros que variam de micrometros a nanômetros, podendo levar à produção de fibras com diâmetro inferior a $1 \mathrm{~nm} .{ }^{20-22}$ As nanofibras obtidas pela técnica de eletrofiação são altamente atrativas para um amplo número de aplicações biomédicas, tecnológicas e ambientais devido à combinação única de elevada razão área superficial/volume, porosidade, flexibilidade, desempenho mecânico, simplicidade de processamento e custo relativamente baixo. ${ }^{20,23-28}$ Destaca-se, ainda, a possibilidade de obtenção de nanoestruturas $1 D$ poliméricas, cerâmicas ou metálicas e, da incorporação de outros nanomateriais e funcionalidades durante ou após o processo de eletrofiação, potencializando o uso de novas arquiteturas compósitas ou híbridas na fabricação de materiais e dispositivos com propriedades finais otimizadas..$^{29-33}$

Devido a essas interessantes características, a produção de nanofibras eletrofiadas (NFs) tem sido alvo de intensa investigação 
e aprimoramento nas últimas décadas, se mostrando promissora tanto em escala laboratorial quanto industrial. Uma consulta à base de dados Web of Science em novembro de 2020 revelou que mais de 25.700 trabalhos envolvendo "eletrofiação" foram publicados na última década (2011-2020). Esse resultado representa um aumento de mais de $540 \%$ quando comparado ao desempenho da década anterior (2001-2010). Frente a esse crescente interesse, nesta revisão abordaremos os avanços da última década na utilização da técnica de eletrofiação para obtenção de NFs com diferentes composições e morfologias. Especificamente, iremos fornecer uma visão geral do estado da arte em relação à aplicação de NFs em diferentes áreas, incluindo biomedicina, meio ambiente, sensoriamento e energia. Por fim, discutiremos as tendências futuras que vêm sendo buscadas para melhorar o desempenho das NFs, bem como a perspectiva real em termos de aplicação industrial. Esta revisão ajudará pesquisadores a compreender, numa perspectiva dos últimos 10 anos, a evolução e os desafios da área e estimulará ainda mais o interesse no desenvolvimento de novos dispositivos baseados em nanofibras eletrofiadas.

\section{ELETROFIAÇÃO}

Embora a primeira patente sobre eletrofiação tenha sido depositada por Cooley em $1902,{ }^{34}$ a produção prática de fibras em escala nanométrica só foi realizada com a redescoberta e popularização da técnica de eletrofiação por Doshi e Reneker em 1995. ${ }^{35}$ O longo intervalo de estagnação pode ser atribuído em grande parte à falta de técnicas capazes de caracterizar com precisão o tamanho das fibras em escala sub-micrométrica. ${ }^{20}$

Em termos gerais, a eletrofiação é um processo eletrohidrodinâmico que resulta no movimento de um fluido por meio da aplicação de um campo eletrostático. ${ }^{36} \mathrm{~A}$ configuração típica de um aparato de eletrofiação é mostrada na Figura 1. Basicamente, o sistema consiste em quatro componentes principais: uma fonte de alta tensão, um reservatório contendo a solução polimérica, um capilar (geralmente uma agulha hipodérmica) e um coletor metálico. ${ }^{31,37} \mathrm{O}$ reservatório que contém a solução polimérica pode ser colocado na vertical ou na horizontal: no primeiro caso, a vazão da solução é controlada principalmente pela gravidade, já na segunda configuração a taxa de ejeção é controlada por uma bomba de ejeção, ${ }^{37}$ como esquematizado na Figura 1.

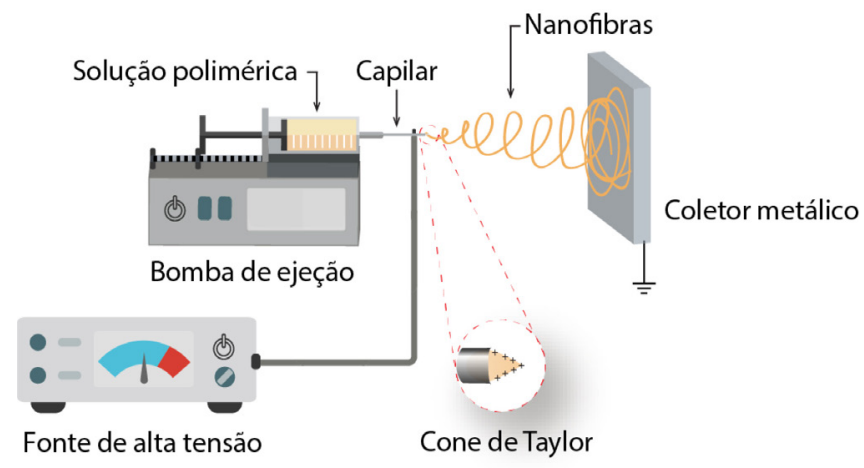

Figura 1. Esquema de um sistema de eletrofiação convencional

No processo de eletrofiação, a solução polimérica contida no reservatório é forçada a passar pelo capilar metálico, o que leva a formação de uma gota que é mantida na ponta do mesmo por forças de tensão superficial. ${ }^{31}$ Em seguida, a aplicação de um campo elétrico, geralmente da ordem de 5 a $30 \mathrm{kV}$, induz a formação de cargas elétricas na superfície do líquido. A repulsão eletrostática e as forças de Coulomb são as principais forças motrizes para induzir a distorção da geometria da gota. ${ }^{20}$ Quando o campo aplicado atinge um valor crítico, as forças elétricas repulsivas superam as forças de tensão superficial e a gota se alonga adquirindo um formato cônico, conhecido como cone de Taylor, a partir do qual um jato carregado da solução é ejetado. ${ }^{20,38,39}$ À medida que o jato se movimenta na direção do coletor, ocorre a evaporação do solvente e a solidificação das NFs, as quais são depositadas, sob a forma de uma membrana, na superfície do coletor aterrado. ${ }^{20,40} \mathrm{Em}$ geral, o mecanismo de formação de fibras eletrofiadas pode ser dividido em quatro etapas consecutivas: (i) formação de cargas elétricas na gota da solução polimérica e formação do cone de Taylor; (ii) extensão do jato carregado ao longo de uma linha reta; (iii) afinamento do jato na presença do campo elétrico e aumento da instabilidade elétrica; (iv) solidificação e coleta do jato como fibra sólida no coletor. ${ }^{41}$ Uma discussão mais detalhada sobre essas etapas pode ser encontrada em outros trabalhos de revisão disponíveis na literatura. ${ }^{14,20,39,41-45}$

Apesar da simples configuração experimental, o processo de eletrofiação é influenciado por diferentes parâmetros que podem ser classificados em parâmetros de solução, parâmetros de processo e parâmetros ambientais, conforme apresentado na Tabela 1. O controle desses parâmetros permite modular a morfologia, o diâmetro (espessura) e o alinhamento das NFs, sendo de extrema importância para direcionar a aplicação das NFs em diferentes áreas. ${ }^{26,31,46}$

\section{Parâmetros de solução}

As propriedades físico-químicas do solvente, do polímero e as interações polímero-solvente têm um papel significativo no processo de eletrofiação e, consequentemente, no diâmetro e morfologia das fibras resultantes. A etapa inicial do processo de eletrofiação envolve o preparo da solução polimérica através da dissolução dos precursores sólidos em um solvente, ou mistura de solventes, apropriado. Os fatores essenciais para a seleção do solvente são sua capacidade de dissolver o polímero e seu ponto de ebulição/volatilidade..$^{26,49,50} \mathrm{O}$ uso de solventes com baixa volatilidade está associado à formação de filmes ou a obtenção de fibras achatadas, na forma de fitas. Por outro lado, se a volatilidade do solvente for muito alta, poderá ocorrer a solidificação do polímero na ponta do capilar, impedindo o processo de obtenção de fibras. ${ }^{51}$

Para obtenção de fibras uniformes e com distribuição estreita de diâmetro, o polímero deve apresentar massa molecular adequada e a solução polimérica deve ter viscosidade apropriada de forma a garantir a formação de um jato contínuo, evitando assim a ruptura do mesmo no trajeto da ponta do capilar até o coletor. ${ }^{50} \mathrm{~A}$ massa molecular do polímero representa o comprimento de sua cadeia polimérica, que por sua vez tem um efeito na viscosidade da solução, uma vez que está relacionada ao grau de emaranhamento das cadeias poliméricas em solução. ${ }^{52}$ Em geral, polímeros com baixa massa molecular não são capazes de serem eletrofiados, pois as cadeias poliméricas não possuem a capacidade de sofrer o emaranhamento necessário para estiramento e manutenção do jato da solução polimérica. ${ }^{52}$ Além disso, a massa molecular do polímero tem um efeito significativo em outras propriedades da solução como tensão superficial, condutividade e resistência dielétrica. ${ }^{26} \mathrm{~A}$ viscosidade da solução também depende da estrutura da cadeia polimérica, da natureza hidrofílica/hidrofóbica, da interação polímero/solvente e da concentração do polímero podendo, portanto, ser controlada pela combinação da concentração polimérica e do tipo de solvente utilizado. ${ }^{47,50} \mathrm{Em}$ geral, uma viscosidade mais baixa favorece a formação de fibras mais finas e homogêneas. No entanto, se a viscosidade for muito baixa, no caso por exemplo de soluções muito diluídas, o emaranhamento das cadeias poliméricas não é suficiente para formação ou manutenção do jato. Nesse caso, 
Tabela 1. Parâmetros do processo de eletrofiação

\begin{tabular}{|c|c|c|c|}
\hline & Parâmetro & Observações & Ref. \\
\hline \multirow{3}{*}{ Parâmetros de solução } & Massa molecular & $\begin{array}{l}\text { A massa molecular do polímero está diretamente relacionada com o com- } \\
\text { portamento reológico da solução. O aumento da massa molecular tende a } \\
\text { favorecer a formação de fibras mais homogêneas. }\end{array}$ & 31,44 \\
\hline & Concentração/Viscosidade & $\begin{array}{l}\text { Observa-se uma tendência de formação de fibras mais espessas com o } \\
\text { aumento da concentração/viscosidade da solução. }\end{array}$ & 44,47 \\
\hline & Condutividade & $\begin{array}{l}\text { O aumento da condutividade tende a favorecer a obtenção de fibras com } \\
\text { menores diâmetros e sem defeitos. }\end{array}$ & 31,43 \\
\hline \multirow{3}{*}{ Parâmetros de processo } & Voltagem aplicada & $\begin{array}{l}\text { Geralmente, o aumento da voltagem favorece a formação de fibras com meno- } \\
\text { res diâmetros. No entanto, a partir de certo ponto o aumento da voltagem pode } \\
\text { estar relacionado com a formação de fibras mais espessas e com defeitos. }\end{array}$ & 43,47 \\
\hline & Vazão da solução & $\begin{array}{l}\text { O aumento da vazão favorece a formação de fibras com maiores diâmetros } \\
\text { e defeitos. }\end{array}$ & 23,31 \\
\hline & Distância de trabalho & $\begin{array}{l}\text { Deve apresentar valor adequado para garantir o alongamento do jato e } \\
\text { evaporação do solvente. Maiores distâncias favorecem a formação de fibras } \\
\text { com menores diâmetros. }\end{array}$ & 43,44 \\
\hline \multirow[t]{2}{*}{ Parâmetros ambientais } & Temperatura & $\begin{array}{l}\text { A temperatura afeta a viscosidade da solução e o processo de evaporação } \\
\text { do solvente. Temperaturas mais elevadas favorecem a formação de fibras } \\
\text { com menores diâmetros. }\end{array}$ & 23,44 \\
\hline & Umidade relativa & $\begin{array}{l}\text { Afeta o processo de evaporação do solvente. Uma maior umidade relativa } \\
\text { tende a induzir a formação de poros na superfície das fibras. }\end{array}$ & 47,48 \\
\hline
\end{tabular}

haverá uma maior tendência à pulverização, resultando na produção de fibras com defeitos na forma de contas (do inglês, beads), que são aglomerados poliméricos. ${ }^{42,53}$ Por outro lado, para altos valores de viscosidade, as cargas elétricas na superfície da gota podem não ser suficientes para gerar a força necessária para formação do jato polimérico. ${ }^{23}$ Além disso, dependendo da volatilidade do solvente empregado, uma viscosidade muito elevada pode favorecer o entupimento do capilar, interrompendo o processo de eletrofiação. ${ }^{53}$

A tensão superficial da solução também desempenha papel crucial para determinação da faixa de concentração/viscosidade ideal a partir da qual fibras contínuas podem ser obtidas. ${ }^{54}$ Como mencionado anteriormente, para que o processo de eletrofiação se inicie, a voltagem aplicada deve ser suficientemente alta para superar a tensão superficial da solução. Sendo assim, em geral, a redução na tensão superficial está associada com a formação de jatos mais estáveis e, consequentemente, de fibras sem defeitos (beads). ${ }^{26}$

A condutividade da solução também pode ser ajustada a fim de se favorecer a formação de fibras homogêneas. Uma maior condutividade está associada com uma maior densidade de cargas na solução, o que favorece o processo de alongamento do jato polimérico e a formação de fibras com menos defeitos e menores diâmetros. A condutividade elétrica está relacionada tanto com o polímero quanto com o solvente e pode ser modulada através da adição de compostos iônicos à solução. ${ }^{26,40}$ Sendo assim, estudos mostram que a adição de sais, íons, polieletrólitos ou polímeros condutores à solução polimérica pode ser usada como estratégia para aumentar a condutividade da solução e obtenção de fibras com melhores propriedades. ${ }^{31}$ No entanto, é importante destacar que, em alguns casos, condutividades acima de um valor crítico podem acarretar na instabilidade do jato, dificultando o processo de obtenção de fibras. ${ }^{49}$

\section{Parâmetros de processo}

As condições de processo também influenciam o design e as propriedades das NFs. Como mencionado anteriormente, o campo elétrico é a força motriz para alongamento da gota e formação do jato que será responsável pela formação das fibras. Se a voltagem elétrica aplicada for muito abaixo do valor crítico, característico do sistema polímero/solvente, o jato da solução polimérica não é estabilizado, o que dificulta a formação de fibras ou leva a obtenção de fibras com defeitos (beads). ${ }^{31}$ Por outro lado, uma voltagem acima pode favorecer um maior alongamento do jato da solução polimérica e a formação de fibras com menores diâmetros..$^{54,55}$ No entanto, estudos mostram que voltagens acima do valor crítico podem favorecer a ejeção de uma maior quantidade de solução polimérica e, consequentemente, levar à formação de fibras mais espessas e não uniformes. ${ }^{26}$

A vazão da solução polimérica também é um parâmetro importante do processo, pois influencia o tamanho da gota, a velocidade do jato e a taxa de transferência de material, exercendo grande influência no diâmetro e morfologia das fibras. ${ }^{26,31}$ Uma vazão ideal, dependente das propriedades do sistema polímero/solvente e dos demais parâmetros de processo, é necessária para formação do cone de Taylor, estabilização do jato e obtenção de fibras homogêneas. ${ }^{49,50}$ Taxas de ejeção muito baixas levam à formação de fibras não uniformes, pois não há transferência de material suficiente. ${ }^{50}$ Vazões acima do valor crítico pode levar à formação de fibras de maiores diâmetros e com defeitos (beads), devido à secagem incompleta do jato durante o percurso da ponta do capilar até o coletor. ${ }^{49}$

A distância entre a ponta do capilar e o coletor, conhecida como distância de trabalho, também deve ser avaliada a fim de se garantir a formação de fibras uniformes. ${ }^{31} \mathrm{~A}$ distância de trabalho influencia a forma e a intensidade do campo elétrico e a taxa de evaporação do solvente. ${ }^{54}$ Uma redução da distância de trabalho pode resultar na supressão de estágios posteriores de alongamento da fibra e evaporação do solvente, podendo acarretar o aumento do diâmetro da fibra, a formação de filmes ou a obtenção de fibras achatadas e/ou com defeitos (beads), devido à evaporação incompleta do solvente..$^{26,47,56}$ Por outro lado, quando a força do campo elétrico é suficiente para manter o processo de eletrofiação, o aumento da distância de trabalho fornece maior percurso para o alongamento do jato e evaporação do solvente, favorecendo a formação de fibras com menores diâmetros. ${ }^{55}$

As propriedades das fibras eletrofiadas também podem ser moduladas pelo redesenho dos coletores e capilares empregados. ${ }^{22,50,57}$ Atualmente, diferentes configurações de coletores podem ser utilizadas com base nas aplicações e características desejadas. Em geral, os coletores mais empregados são os estáticos recobertos com folha de alumínio que levam a obtenção de fibras na forma randômica. ${ }^{31}$ No entanto, existem outros tipos que possibilitam a 
obtenção de fibras alinhadas, como os coletores de tambor rotativo, de fio rotativo, de eletrodos paralelos, tipo grade, de anel duplo, entre outros. ${ }^{50,57,58}$ Além disso, há coletores que possibilitam a obtenção de estruturas esponjosas compostas por fibras, como é o caso do coletor imerso. ${ }^{29}$ Variando-se a geometria do capilar empregado é possível obter NFs com diferentes estruturas, desde estruturas tipicamente sólidas até ocas, do tipo núcleo-casca (do inglês, core-shell), Janus, entre outras. ${ }^{59}$

\section{Parâmetros ambientais}

Outros parâmetros a serem considerados no processo de eletrofiação são as condições ambientais de temperatura e umidade relativa. Em ambientes com menor umidade relativa observa-se uma maior tendência para rápida evaporação do solvente o que, geralmente, acarreta a formação de fibras mais finas. ${ }^{49}$ No entanto, taxas de evaporação do solvente muito elevadas podem levar à solidificação do polímero na ponta do capilar, impedindo o processo de formação de fibras. ${ }^{23,26} \mathrm{O}$ aumento da umidade relativa pode levar a formação de poros na superfície das fibras. ${ }^{47} \mathrm{~A}$ formação de poros está relacionada ao processo de evaporação do solvente que ocorre devido a separação de fase da solução polimérica durante a formação da fibra. ${ }^{38,48}$ Com relação à temperatura, estudos demostram que o aumento da temperatura pode induzir a formação de fibras com menores diâmetros por dois mecanismos distintos: aumentando a taxa de evaporação do solvente e diminuindo a viscosidade da solução polimérica. ${ }^{49}$

\section{CARACTERIZAÇÃO DE NANOFIBRAS ELETROFIADAS}

O grande interesse dos pesquisadores pelo estudo das NFs se deve às suas notáveis propriedades que possibilitam o desenvolvimento de materiais funcionais para diversas aplicações. Para melhor compreender as propriedades e viabilizar a aplicação é necessário realizar uma rigorosa investigação das propriedades das NFs e, para isso, diferentes técnicas de caracterização podem ser empregadas. ${ }^{60,61}$

Para avaliação das propriedades morfológicas, incluindo diâmetro, distribuição do diâmetro, orientação e rugosidade, técnicas microscópicas como: microscopia eletrônica de varredura (MEV), microscopia eletrônica de varredura com emissão de campo (MEV-FEG), microscopia eletrônica de transmissão (MET) e microscopia de força atômica (MFA) são amplamente empregadas. A determinação do diâmetro é feita com o auxílio de softwares de análises de imagens. Dentre os programas disponíveis, o ImageJ, desenvolvido pelo NIH (do inglês, National Institutes of Health), tem sido o mais empregado. ${ }^{62}$ Autores que fazem uso do software ImageJ relatam usualmente a utilização de 50 a 100 medidas manuais para se obter o diâmetro médio das NFs. ${ }^{62-64}$

A porosidade tem um efeito determinante no desempenho das NFs desenvolvidas especialmente para aplicações em sistemas de filtração, catálise, sensores e engenharia de tecidos. ${ }^{29,65}$ As membranas nanofibrosas obtidas pela técnica de eletrofiação podem apresentar dois tipos de poros: poros nas superfícies ou dentro das fibras e poros entre as fibras. ${ }^{52}$ Dentre as técnicas disponíveis para análise da porosidade, do tamanho e distribuição dos poros, as mais empregadas são as técnicas de microscopia mencionadas anteriormente e técnicas de porosimetria. No último caso, as NFs têm sido caracterizadas por técnicas de adsorção molecular, usando principalmente $\mathrm{N}_{2}$ como adsorvente. ${ }^{60}$ Geralmente, são realizadas medidas de adsorção em função da pressão e os dados obtidos são analisados pela teoria de adsorção física BET (Brunauer-Emmett-Teller), fornecendo informações sobre os poros e a área de superfície do nanomaterial. ${ }^{13,20}$

As propriedades químicas da superfície são comumente avaliadas por espectroscopia de fotoelétrons induzidos por raios $\mathrm{X}$ (XPS, do inglês $X$-ray photoelectron spectroscopy), espectroscopia Raman e espectroscopia na região do infravermelho. ${ }^{66,67}$ Técnicas de ressonância magnética nuclear (RMN) também são utilizadas, principalmente quando são empregados mais de um polímero para obtenção das fibras. ${ }^{26}$ No caso de nanofibras contendo mais de um componente, essas técnicas permitem ainda a avaliação das interações intermoleculares entre os diferentes constituintes do material. ${ }^{66}$ Medidas de ângulo de contato também são muito empregadas para avaliação das propriedades químicas da superfície, fornecendo informações sobre a natureza hidrofóbica/hidrofílica do material. ${ }^{52,58,68}$

A fim de se obter informações sobre a cristalinidade das amostras, além da MET, outras formas de caracterização podem ser empregadas, incluindo as técnicas de difração de raios $\mathrm{X}$, microscopia de luz polarizada e calorimetria de varredura diferencial (DSC, do inglês differential scanning calorimeter) ${ }^{60}$ A técnica de DSC permite identificar eventos térmicos do material, como temperatura de fusão, temperatura de cristalização e temperatura de transição vítrea. ${ }^{23}$ Além disso, a estabilidade térmica das nanofibras pode ser avaliada por termogravimetria (TGA, do inglês thermal gravimetric analysis).

A análise das propriedades mecânicas das membranas formadas pelas NFs é de extrema importância para aplicações biomédicas e em sistemas de filtração, e pode ser realizada empregando-se técnicas convencionais de ensaio de tração. ${ }^{23,26}$ Devido à dificuldade em isolar e manipular as NFs individualmente, a caracterização mecânica de uma nanofibra é desafiadora. ${ }^{60}$ Nesse caso, diferentes autores reportam o uso da técnica de MFA, através da qual o módulo de Young pode ser calculado a partir das curvas de força-deslocamento obtidas pela flexão de uma única fibra colada na ponta do cantilever do microscópio. ${ }^{23,52,60}$ É importante ressaltar que as propriedades mecânicas das membranas nanofibrosas são fortemente afetadas pela porosidade e orientação das NFs, sendo assim, o comportamento atribuído à membrana não pode ser associado ao comportamento de uma única fibra. ${ }^{60}$

\section{TIPOS DE NANOFIBRAS}

A técnica de eletrofiação tem sido utilizada para produzir fibras ultrafinas de vários materiais tanto na forma de fibras individuais quanto na forma de mantas/membranas de fibras dispostas de forma orientada ou randômica. ${ }^{69}$ Os materiais mais comumente empregados são polímeros orgânicos fundidos ou na forma de solução. No entanto, moléculas pequenas com capacidade de auto-organização também podem ser diretamente eletrofiadas, caso apresentem emaranhamento molecular suficiente para estabilização do jato durante o processo de eletrofiação. Nesse caso, o fator chave é a presença de interações moleculares que leva à formação de estruturas automontadas em soluções altamente concentradas. ${ }^{20}$ Neste contexto, Celebioglu e colaboradores reportaram a obtenção de nanofibras a partir de soluções de ciclodextrinas. ${ }^{70,71}$

NFs poliméricas são as mais comuns na literatura, representando aproximadamente $60 \%$ das publicações sobre nanofibras eletrofiadas nos últimos 10 anos. Tanto polímeros naturais quanto polímeros sintéticos, ou uma mistura de ambos, podem ser empregados na fabricação de NFs, desde que possam ser dissolvidos em solventes apropriados para obter soluções ou fundidos sem degradação. ${ }^{50}$ Dentre os polímeros naturais, um dos mais empregados é a quitina, precursor da quitosana. ${ }^{72}$ Além da quitina, também são encontrados trabalhos na literatura reportando o uso de colágeno, gelatina, quitosana, ácido hialurônico, celulose, alginato, entre outros polímeros naturais para obtenção de NFs a partir da técnica de eletrofiação. ${ }^{73}$ No entanto, é importante ressaltar que a preparação de NFs a partir de polímeros naturais puros ainda é um desafio devido ao peso molecular 
relativamente baixo de alguns desses materiais e à disponibilidade limitada de solventes que sejam ao mesmo tempo adequados para o processo de eletrofiação e para dissolvê-los. ${ }^{74}$ No caso dos polímeros sintéticos, uma extensa variedade de polímeros vem sendo empregada, destacando-se o poli(ácido lático) (PLA), poli(álcool vinílico) (PVA), poliamida 6 (PA6, também conhecido por seu nome comercial Nylon $^{\circledR}$ ) e poli(óxido de etileno) (PEO)..$^{24,75,76}$ Seja composta por polímeros sintéticos ou naturais, as propriedades das NFs poliméricas são afetadas principalmente pelos aspectos morfológicos. ${ }^{38}$ Nesse sentido, uma das propriedades mais importantes relacionadas com a produção das nanofibras por eletrofiação é o seu diâmetro. ${ }^{31}$ Além do diâmetro, a aparência externa da fibra é outra característica que pode ser modulada sendo o mais comum a obtenção de NFs com superfície lisa (Figura 2a) ou porosa (Figura 2b). Como mencionado anteriormente, dependendo dos parâmetros empregados, a técnica de eletrofiação pode levar ainda a formação de NFs com contas ou beads (Figura 2c).

Com a popularização da técnica de eletrofiação e aumento do interesse por parte dos cientistas de diversas áreas do conhecimento, novos avanços foram alcançados na adaptação da técnica para obtenção de NFs de outros materiais. ${ }^{20}$ NFs de carbono, por exemplo, podem ser obtidas por meio do tratamento térmico de NFs poliméricas. Nesse caso, duas etapas estão envolvidas: (i) estabilização da estrutura de fibra em temperaturas entre 200 e $300{ }^{\circ} \mathrm{C}$ e (ii) carbonização a $400-1800^{\circ} \mathrm{C}$ em atmosfera de gás inerte..$^{85}$ Após esse processo, materiais a base de carbono são obtidos sem comprometer a morfologia fibrosa. ${ }^{20}$ A poliacrilonitrila (PAN) é o polímero precursor mais amplamente utilizado para obtenção de NFs de carbono devido à sua boa capacidade de fiação e alto rendimento de carbono (> 50\%), bem como às propriedades mecânicas superiores das NFs resultantes. ${ }^{86}$

Em 2003, Li e Xia reportaram pela primeira vez a produção de NFs cerâmicas (inorgânicas) a partir da combinação da técnica de eletrofiação com o método sol-gel. ${ }^{87}$ Tal feito representou um avanço tanto para as potencialidades da técnica de eletrofiação quanto para os métodos de obtenção de materiais cerâmicos. Nesse caso, a produção das NFs cerâmicas envolve três etapas principais: (i) preparo de uma suspensão coloidal estável (sol) contendo o precursor sol-gel, o polímero e o solvente (ou mistura de solventes) adequado; (ii) obtenção das NFs por meio da técnica de eletrofiação; e (iii) formação das NFs cerâmicas por meio da remoção seletiva da matriz polimérica (fase orgânica) por uma etapa de tratamento térmico. ${ }^{88} \mathrm{~A}$ combinação do método sol-gel na produção das NFs é um recurso que possibilita a obtenção de soluções/suspensões contendo os precursores metálicos (alcóxidos metálicos) com viscosidade adequada e baixa taxa de hidrólise garantindo também uma distribuição homogênea dos íons metálicos ao longo das fibras formadas. ${ }^{20}$ Outra estratégia que resulta na formação de NFs cerâmicas é a utilização de precursores metálicos na forma de íons (sais metálicos) dispersos em uma solução polimérica a qual atua como matriz estrutural, além de conferir viscosidade necessária para a formação das fibras durante a eletrofiação. ${ }^{30}$ Essa segunda estratégia tem sido amplamente reportada como igualmente eficiente além de apresentar como vantagem a simplicidade no preparo das soluções/suspensões. ${ }^{88}$ Assim como no procedimento anterior, após a obtenção das mantas de NFs poliméricas, a etapa final envolve o tratamento térmico que será determinante para a manutenção da estrutura fibrosa das NFs durante a remoção da matriz polimérica e formação da fase cerâmica. ${ }^{30,89} \mathrm{~A}$ morfologia e propriedades das NFs são altamente afetadas pelas condições (temperatura e atmosfera de gás) empregadas durante a etapa de calcinação. ${ }^{90,91}$ Temperaturas moderadas são ideais para a obtenção de NFs com superfícies lisas, enquanto o uso de temperaturas mais elevadas está associado à obtenção de NFs cerâmicas porosas. ${ }^{11} \mathrm{O}$ aumento adicional da temperatura pode resultar no crescimento das partículas cristalinas e, consequentemente, na diminuição ou até mesmo eliminação dos poros evoluindo para uma nanofibra de estrutura sólida. ${ }^{92}$ Considerando a formação da fase cerâmica, quando os íons metálicos são providos por meio de precursores iônicos, o óxido metálico será formado pelo processo
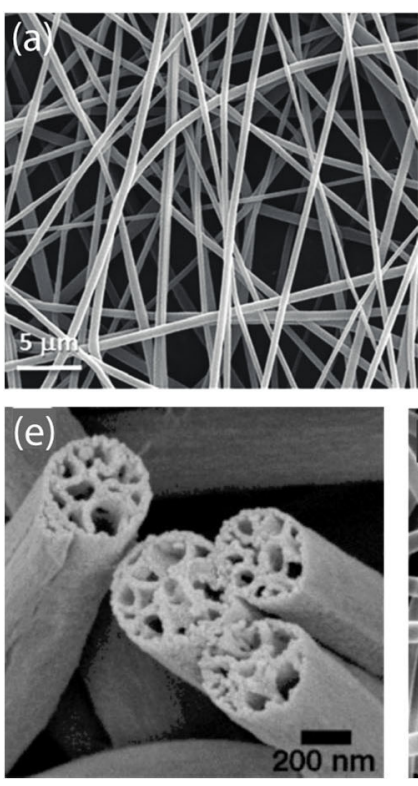
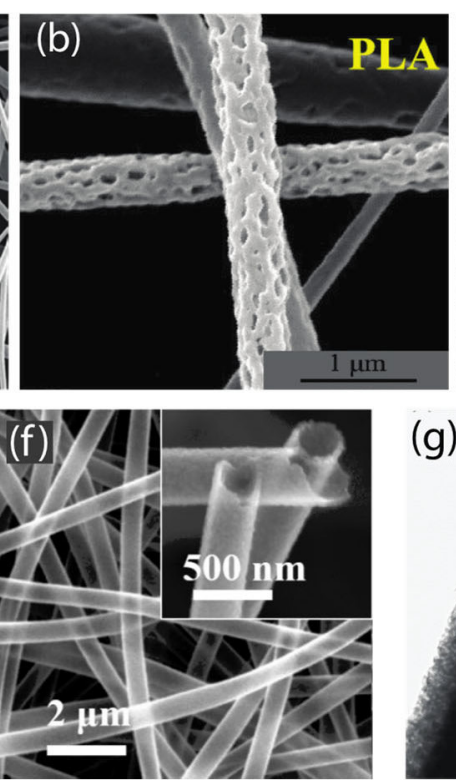
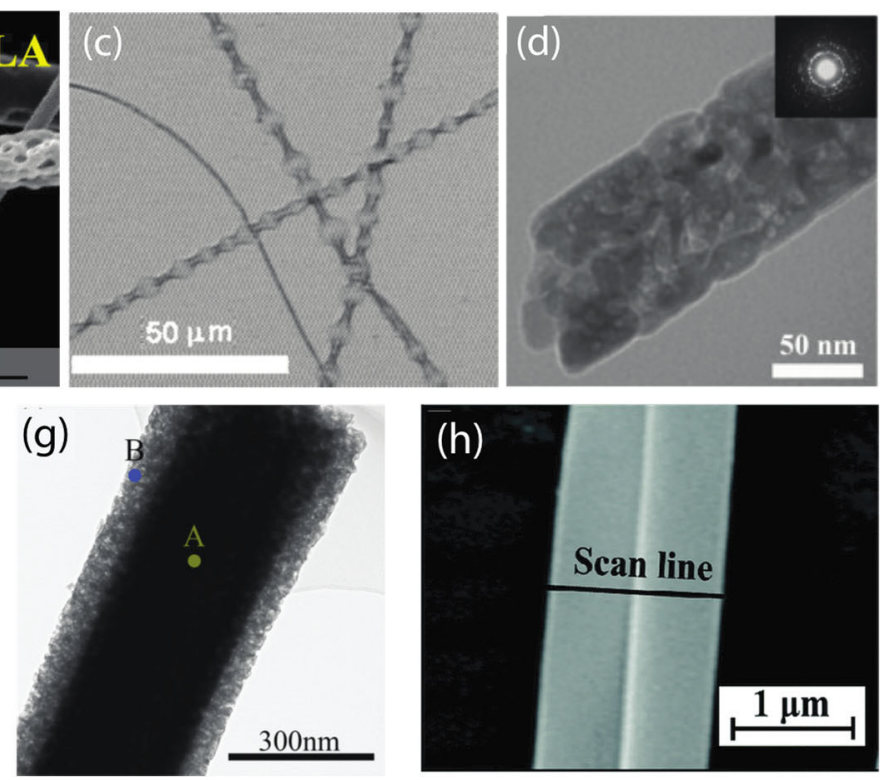

Figura 2. Imagens de microscopia eletrônica de diferentes tipos de nanofibras eletrofiadas: (a) NFs poliméricas de superfície lisa. Reproduzida com permissão da referência 77. Copyright 2018 Elsevier. (b) NFs poliméricas de poli(ácido lático) porosas. Reproduzida com permissão da referência 78 . Copyright 2019 American Chemical Society. (c) NFs poliméricas de poli(metil metacrilato) com beads. Reproduzida com permissão da referência 79 . Copyright 2005 American Chemical Society. (d) NFs de hidroxiapatita. Reproduzida com permissão da referência 80 . Copyright 2009 John Wiley \& Sons. (e) NFs porosas de TiO.

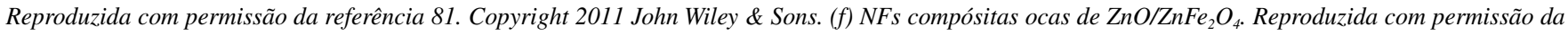
referência 82. Copyright 2019 American Chemical Society. (g) NFs coaxiais de $\mathrm{CaCu}_{3} \mathrm{Ti}_{4} \mathrm{O}_{12}\left(\right.$ núcleo) e Al $\mathrm{O}_{3}($ casca). Reproduzida com permissão da referência 83. Copyright 2018 American Chemical Society. (h) NFs Janus de [Fe $\left.{ }_{3} \mathrm{O}_{4} / \mathrm{PVP}\right] / /\left[\mathrm{Tb}(\mathrm{BA})_{3}\right.$ phen/PVP]. Reproduzida com permissão da referência 84. Copyright 2019 The Royal Society of Chemistry 
de coprecipitação, seguindo as etapas de nucleação, crescimento e coalescência, levando ao arranjo unidimensional de fibra. ${ }^{93}$ No caso dos precursores do tipo alcóxido, a fase inorgânica será formada por reações de hidrólise e condensação tal como no método sol-gel. Em outras palavras, os grupos alcóxidos são substituídos por grupos hidroxila e, na sequência, ocorre uma reação de condensação onde a ligação metal-oxigênio é formada e moléculas de água são eliminadas como subproduto. ${ }^{93}$

Os óxidos metálicos mais comumente reportados na última década para a fabricação de nanofibras cerâmicas são $\mathrm{SnO}_{2}, \mathrm{ZnO}$, $\mathrm{In}_{2} \mathrm{O}_{3}$ e $\mathrm{TiO}_{2} \cdot{ }^{30,88}$ No entanto, é importante destacar que a técnica de eletrofiação não se limita à fabricação de NFs de óxidos binários, NFs de outras fases cerâmicas, como é o caso de NFs de hidroxiapatita $\left(\mathrm{Ca}_{10}\left(\mathrm{PO}_{4}\right)_{6}(\mathrm{OH})_{2}\right)$ (Figura $\left.2 \mathrm{~d}\right),{ }^{80}$ também podem ser obtidas pela técnica. Além disso, combinando os parâmetros de tratamento térmico e de eletrofiação, precursores metálicos e composição das soluções, a característica estrutural das NFs cerâmicas pode variar resultando em estruturas sólidas, ${ }^{89,94,95}$ porosas, ${ }^{96,97}$ ocas, ${ }^{82,98}$ núcleo-casca, ${ }^{98}$ Janus $^{82}$ e hierárquicas. ${ }^{99-101}$ Chen e colaboradores, por exemplo, reportaram a obtenção de NFs porosas de $\mathrm{TiO}_{2}$ a partir da eletrofiação de uma microemulsão contendo o alcóxido de titânio. ${ }^{81}$ Após o processo de calcinação a $500{ }^{\circ} \mathrm{C}$, NFs mesoporosas de $\mathrm{TiO}_{2}$ com área superficial de $75,8 \mathrm{~m}^{2} \mathrm{~g}^{-1}$ e poros da ordem de $22,7 \mathrm{~nm}$ foram obtidas, conforme ilustrado na Figura 2e.

As NFs cerâmicas eletrofiadas exibem uma série de propriedades e características únicas, como morfologia $1 D$, alta estabilidade química e térmica, alta área de superfície e também a possibilidade de modulação da estrutura conforme discutido anteriormente. ${ }^{30}$ Outra característica importante dos materiais cerâmicos, obtidos na forma de NFs, é a possibilidade de conformação como membranas (suportadas ou autossustentáveis) que podem ser convenientemente manipuladas e manuseadas. ${ }^{102}$ Especificamente, membranas formadas por NFs contendo $\mathrm{SiO}_{2}$ amorfo tem ganhado destaque por apresentarem maior resistência mecânica, além das vantagens atribuídas aos materiais inorgânicos já mencionadas. ${ }^{97,103}$

NFs metálicas também podem ser obtidas empregando-se a técnica de eletrofiação. Nesse caso, o método empregado envolve tipicamente duas etapas de tratamento térmico: (i) calcinação no ar para remoção da fase orgânica como descrito anteriormente, obtendo nanofibras de óxido metálico e então (ii) redução em uma atmosfera redutiva para conversão dos óxidos metálicos em metais. Dependendo da atmosfera empregada, se a temperatura para o tratamento térmico na primeira etapa exceder a temperatura de decomposição do óxido metálico, NFs metálicas podem ser formadas diretamente. ${ }^{20}$

Adicionalmente, NFs contendo mais de um componente, inorgânico ou orgânico, podem ser obtidas por misturas de soluções com diferentes composições ou por processos de pós-funcionalização das NFs. ${ }^{14,31}$ Tais nanofibras são conhecidas como compósitas ou híbridas, quando constituídas por materiais orgânicos e inorgânicos. A obtenção de NFs compósitas e/ou híbridas tem sido foco de intensas pesquisas na última década por possibilitarem o sinergismo de propriedades entre diferentes tipos de materiais, potencializando suas propriedades finais..$^{30,31}$ Outra vantagem da combinação de mais de um componente é a possibilidade de produção de fibras utilizando materiais que isoladamente não seriam capazes de produzir fibras, como é o caso de alguns polímeros condutores e polímeros naturais. ${ }^{69,74}$ Devido às limitações do baixo peso molecular e à falta de solventes adequados, até o momento, apenas alguns polímeros condutores, como polianilina (PANI) e polipirrol (PPy), foram eletrofiados isoladamente. ${ }^{69}$ Vale ainda destacar que, na literatura, muitas vezes as definições de NFs compósitas e híbridas se misturam e se confundem e que as definições descritas acima são as definições adotadas ao longo deste trabalho.
As NFs contendo mais de uma fase podem ser obtidas pela combinação de: polímeros naturais e sintéticos, nanopartículas inorgânicas (quantum dots, óxidos metálicos e metálicas), nanomateriais a base de carbono (nanotubos de carbono, grafeno e seus derivados), dentre outros materiais. As NFs compósitas e híbridas podem ser obtidas seguindo-se duas estratégias de síntese: (i) pela combinação dos diferentes materiais durante o processo de eletrofiação ou (ii) pela incorporação do material de interesse após o processo de eletrofiação. ${ }^{31}$ Dentre essas, a mais utilizada envolve a mistura dos materiais de interesse, ou ainda de seus precursores, na fase de preparo da solução polimérica com a posterior eletrofiação da solução contendo os diferentes materiais. ${ }^{24}$ Tratando-se de NFs compósitas puramente inorgânicas, elas devem ainda ser submetidas ao tratamento térmico, assim como descrito anteriormente. Tal abordagem resulta na obtenção de nanofibras compostas por múltiplas fases dispersas aleatoriamente ao longo da fibra. Como exemplo, pode-se citar o trabalho publicado por Liu e colaboradores, no qual foram obtidas nanofibras compósitas ocas contendo as fases $\mathrm{ZnO}$ e $\mathrm{ZnFe}_{2} \mathrm{O}_{4}$ (Figura 2f). ${ }^{82}$

Outra alternativa é a produção de fibras coaxiais com estruturas do tipo núcleo-casca (core-shell) e composição dissimilar para cada uma das componentes. ${ }^{104,105} \mathrm{O}$ processo de eletrofiação coaxial é uma modificação ou extensão da técnica de eletrofiação tradicional, em que as NFs são incorporadas uma dentro da outra por meio do uso de agulhas coaxiais que possibilitam a ejeção e formação das fibras de forma independente e concêntrica sem a mistura de fases. ${ }^{105}$ As NFs coaxiais podem ser compostas por combinação de materiais orgânico/ orgânico, ${ }^{106,107}$ inorgânico/inorgânico ${ }^{98,108}$ e orgânico/inorgânico. ${ }^{109}$ A fabricação de NFs coaxiais por eletrofiação têm a vantagem de possibilitar o controle da espessura da casca e do núcleo e, assim, modular as propriedades finais do material. ${ }^{104}$ Combinando duas fases inorgânicas, Chi et al. reportaram a obtenção de NFs coaxiais para aplicações em energia. Imagens de MET (Figura 2g) revelaram que as NFs obtidas eram consistentes com estruturas do tipo núcleo-casca, em que o núcleo de $\mathrm{CaCu}_{3} \mathrm{Ti}_{4} \mathrm{O}_{12}$ apresentou diâmetro de $200 \mathrm{~nm}$ e a camada de revestimento, de $\mathrm{Al}_{2} \mathrm{O}_{3}, 50 \mathrm{~nm}$ de espessura. ${ }^{83} \mathrm{De}$ forma mais simples, estruturas do tipo núcleo-casca também podem ser obtidas por processos de pós-funcionalização após a fabricação das NFs por eletrofiação, como no trabalho de Han e colaboradores. ${ }^{110}$ Nesse trabalho, os autores obtiveram mantas autossustentáveis compostas por nanofibras coaxiais de carbono e $\mathrm{MnO}_{2}$. Para isso, mantas de NFs de poliimida (PI) com polivinilpirrolidona (PVP) foram preparadas e, na sequência, submetidas a tratamento térmico a $1000^{\circ} \mathrm{C}$ para obtenção de NFs de carbono. A combinação dos dois polímeros (PI e PVP) é um exemplo de ajuste da composição da solução polimérica para melhor desempenho no processo de produção das NFs, uma vez que uma solução contendo apenas PI não apresenta as especificações de viscosidade e densidade de carga necessárias para o processo de eletrofiação. Após a obtenção das NFs de carbono, a estrutura do tipo núcleo-casca foi obtida por imersão das nanofibras de carbono em solução de $\mathrm{KMnO}_{4}$ para formação do $\mathrm{MnO}_{2}$ na superfície das NFs. A espessura da camada de $\mathrm{MnO}_{2} \mathrm{e}$, consequente, as propriedades elétricas no material final foram moduladas pelo tempo de imersão das NFs na solução de permanganato.

Por fim, outra estratégia que também resulta em nanoestruturas compósitas ou híbridas é a obtenção de NFs com configuração do tipo Janus. ${ }^{111}$ Com denominação inspirada no deus da mitologia romana, as estruturas do tipo Janus vêm despertando grande interesse dos pesquisadores e cientistas pois além das propriedades combinadas dos materiais constituintes, essas estruturas podem também apresentar multifuncionalidade devido às faces com composição diferente e independentes. ${ }^{111}$ As nanofibras Janus podem ser obtidas por meio de um sistema conjugado com uma configuração de agulhas paralelas, onde duas soluções são respectivamente carregadas em duas seringas 
separadas. Recentemente, Wang e colaboradores ${ }^{84}$ reportaram a obtenção de NFs de PVP com estrutura Janus direcionalmente alinhadas contendo de um lado nanopartículas magnéticas $\left(\mathrm{Fe}_{3} \mathrm{O}_{4} / \mathrm{PVP}\right)$ e do outro lado um complexo metálico com propriedades luminescentes ( $\mathrm{Tb}(\mathrm{BA})_{3}$ phen/PVP) (Figura $2 \mathrm{~h}$ ). Nesse caso, as NFs são híbridas em cada unidade formando uma estrutura Janus final também híbrida, possibilitando a obtenção de um material bifuncional com propriedades magnéticas e luminescentes independentes.

\section{APLICAÇÕES DE NANOFIBRAS ELETROFIADAS}

Os avanços no desenvolvimento de novos materiais, da técnica de eletrofiação e das técnicas de caracterização vêm permitindo que as NFs produzidas sejam aplicadas em áreas biomédicas, ambientais, de (bio)sensoriamento químico e de conversão e armazenamento de energia, como será discutido nas próximas seções.

\section{Aplicações biomédicas}

Nas últimas duas décadas, a eletrofiação surgiu como uma estratégia promissora para a produção de nanomateriais para aplicações biomédicas. ${ }^{29,49,63,68,112}$ Nesse sentido, a técnica de eletrofiação vem sendo amplamente utilizada para o desenvolvimento de sistemas de liberação controlada, membranas para cicatrização de feridas e regeneração tecidual e no desenvolvimento de (bio)sensores vestíveis. ${ }^{113-115}$ A Tabela 2 apresenta alguns exemplos de aplicações de NFs na área biomédica reportados na última década.
A reparação ou regeneração de tecidos envolve a integração de materiais de suporte, células e/ou fatores biológicos para promover o crescimento do tecido, fornecendo uma combinação adequada de suporte mecânico, orientação topográfica e instrução bioquímica para as células. ${ }^{20,137,138}$ No desenvolvimento de materiais de suporte para o cultivo de células (do inglês, scaffolds), é de extrema importância que o mesmo apresente características semelhantes à matriz extracelular (MEC) em termos de composição, arquitetura e outras propriedades. ${ }^{113}$ Nesse sentido, as NFs vêm sendo amplamente exploradas para fabricação de scaffolds devido à sua capacidade única de mimetizar a composição, escala de comprimento e arquitetura típica da MEC. Além disso, a atuação desses suportes formados por NFs permite uma elevada organização celular, além de melhorar a adesão, migração, proliferação, diferenciação celular e transporte de nutrientes, reduzindo assim a apoptose e necrose celular. ${ }^{137}$

O método convencional de eletrofiação leva à formação de NFs arranjadas em estruturas $3 D$ com múltiplas fibras aleatoriamente dispostas e interconectadas e com alta porosidade. Essa estrutura é altamente favorável para o desenvolvimento de materiais utilizados na regeneração tecidual de cartilagem, pele, ossos e vasos sanguíneos. ${ }^{113,137,139}$ Também é encontrado na literatura o potencial para uso das NFs como material para enxerto cirúrgico. ${ }^{118}$ Yin et al. produziram scaffolds baseados em NFs formadas pela blenda de poli(L-ácido láctico-co-e-caprolactona) (P(LLA-CL)) com colágeno e quitosana. A otimização da composição das NFs permitiu a produção de estruturas com propriedades mecânicas adequadas para desenvolvimento de prótese vascular, além de

Tabela 2. Exemplos de NFs desenvolvidas para aplicações biomédicas

\begin{tabular}{|c|c|c|c|c|}
\hline Aplicação & & Material & Tipo de NF & Ref. \\
\hline \multirow{6}{*}{ Engenharia de tecidos } & & PVA/BTCA ${ }^{\mathrm{a}}$ e PVA/ácido cítrico & \multirow{4}{*}{ NFs randomicamente orientadas } & 116 \\
\hline & 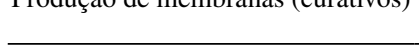 & $\mathrm{PCL}^{\mathrm{b}} / \mathrm{CA}^{\mathrm{c}}$ e $\mathrm{CHI}^{\mathrm{d}} / \mathrm{PEO}$ & & 117 \\
\hline & Produção de materiais para enxerto & $\mathrm{Col}^{\mathrm{e}} / \mathrm{CHI} / \mathrm{P}(\mathrm{LLA}-\mathrm{CL})^{\mathrm{f}}$ & & 118 \\
\hline & \multirow{3}{*}{ Produção de scaffolds } & $\mathrm{CA}^{\mathrm{c}}$ & & 119 \\
\hline & & PLGA $^{g}$ e PLGA/Gelatina/MSNPs ${ }^{\mathrm{h}}$ & NFs alinhadas & 120 \\
\hline & & $\begin{array}{c}\text { Alginato/PEO/lecitina/células } \\
\text { ósseas }\end{array}$ & NFs carregadas com células & 121 \\
\hline \multirow{6}{*}{$\begin{array}{l}\text { Entrega controlada } \\
\text { de drogas }\end{array}$} & \multirow{2}{*}{$\begin{array}{l}\text { Produção de curativo } \\
\text { associado à droga }\end{array}$} & PLLA/DMOG ${ }^{\mathrm{i}} / \mathrm{MSNPs}^{\mathrm{h}}$ & NFs coaxiais alinhadas & 122 \\
\hline & & Alginato/PCL ${ }^{b}$ & \multirow{3}{*}{ NFs do tipo core-shell } & 123 \\
\hline & Produção de membranas de & $\mathrm{PLGA}^{\mathrm{g}} / \mathrm{HA}^{\mathrm{j}} / \mathrm{Col}^{\mathrm{e}} / \mathrm{amoxicilina}$ & & 106 \\
\hline & reparação tecidual guiada & PEO/BMP-2/PEG-PCL & & 124 \\
\hline & \multirow{2}{*}{$\begin{array}{l}\text { Produção de cápsula de } \\
\text { revestimento para fármaco }\end{array}$} & ECl/cetoprofeno & \multirow{2}{*}{ NFs triaxiais } & 125 \\
\hline & & CAc/ibuprofeno & & 126 \\
\hline \multirow{11}{*}{ Sensores vestíveis } & \multirow{10}{*}{$\begin{array}{l}\text { Sensores de pressão/estímulo } \\
\text { mecânico (formação de NGs) }\end{array}$} & $\mathrm{PVDF}^{\mathrm{m}}$ & \multirow{6}{*}{ NFs randomicamente orientadas } & 127 \\
\hline & & $\mathrm{SF}^{\mathrm{n}}$ & & 128 \\
\hline & & PAN/grafeno & & 129 \\
\hline & & gelatina & & 130 \\
\hline & & $\mathrm{PVDF}^{\mathrm{m}}$ & & 131 \\
\hline & & PTFE$/ \mathrm{PEO}$ & & 132 \\
\hline & & PU/óxido de grafeno & \multirow{3}{*}{ NFs alinhadas } & 133 \\
\hline & & DTPUq/CNTs/ & & 134 \\
\hline & & $\mathrm{PVDF}^{\mathrm{m}} / \mathrm{PEDOT}$ & & 135 \\
\hline & & PAN/PANI & NFs híbridas do tipo core-shell & 107 \\
\hline & Detecção epidérmica de glucose & $\mathrm{CA}^{\mathrm{c}} / \beta-\mathrm{CD}^{\mathrm{r}} / \mathrm{GOx}^{\mathrm{s}}$ & NFs randomicamente orientadas & 136 \\
\hline
\end{tabular}

${ }^{\mathrm{a}} \mathrm{BTCA}$ - ácido 1,2,3,4-butanotetracarboxílico; ${ }^{\mathrm{b}} \mathrm{PCL}$ - policaprolactona; ${ }^{\mathrm{c}} \mathrm{CA}$ - acetato de celulose; ${ }^{\mathrm{d}} \mathrm{CHI}$ - quitosana; ${ }^{\mathrm{e}} \mathrm{Col}$ - colágeno; ${ }^{\mathrm{f}} \mathrm{P}(\mathrm{LLA}-\mathrm{CL})$ - poli $(\mathrm{L}$-ácido

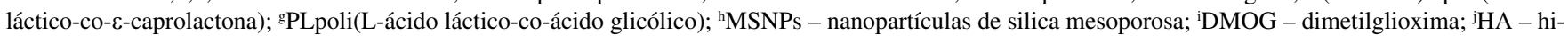
droxiapatita; ${ }^{\mathrm{k}} \mathrm{BMP}-2$ - proteína morfogenética humana; ${ }^{\mathrm{EC}}$ - etilcelulose; ${ }^{\mathrm{m} P V D F}$ - fluoreto de polivinilideno; ${ }^{\mathrm{n} S F}$ - fibroína; ${ }^{\circ} \mathrm{PTFE}$ - politetrafluoretileno; ${ }^{\mathrm{p} P U}$ - poliuretano; ${ }^{\mathrm{q}} \mathrm{DTPU}$ - poliueratano termoplástico modificado com dopamina; ${ }^{\mathrm{r}} \beta$-CD - $\beta$-ciclodextrina; ${ }^{\mathrm{s}} \mathrm{GOx}-\mathrm{glucose}$ oxidase. 
favorecer a proliferação de células endoteliais (células que recobrem o interior dos vasos sanguíneos), conforme mostram as micrografias apresentadas na Figura 3a. ${ }^{118}$ Chakraborty e colaboradores reportaram o desenvolvimento de estruturas para regeneração/ reparação óssea, onde soluções de acetato de celulose preparadas em mistura de acetona-água foram utilizadas para produção de NFs com diâmetros médios de 300-600 nm. ${ }^{119} \mathrm{O}$ material desenvolvido foi testado in vitro sob cultura de células de osteoblastos resultando no crescimento e proliferação celular, indicando viabilidade do material para a área de engenharia de tecidos ósseos. Çay et al. reportaram o desenvolvimento de NFs de PVA reticulado com ácidos policarboxílicos com elevada área de superfície e de fácil reticulação. ${ }^{116}$ Os resultados dos testes in vitro mostraram que as NFs desenvolvidas favoreceram a aderência e proliferação de células de queratina cutânea humana, evidenciando que o nanomaterial obtido é promissor para aplicações reais como curativo de pele. Tecidos formadores de músculos, ligamentos e tendões tem sua estrutura biológica organizada em feixes altamente alinhados. Como mencionado anteriormente, através da adaptação do coletor metálico utilizado no processo de eletrofiação, é possível obter fibras alinhadas que mimetizam esses tecidos. ${ }^{140}$ Mehrasa e colaboradores desenvolveram scaffolds baseados em NFs alinhadas de poli(L-ácido láctico-co-ácido glicólico) (PLGA) e gelatina funcionalizadas com nanopartículas de sílica, utilizando coletor rotativo operando a 2000 rpm. As NFs alinhadas se mostraram promissoras como suporte para proliferação celular. ${ }^{120}$

Ainda na área de engenharia de tecidos, destaca-se a utilização da técnica de eletrofiação de células (C-ES, do inglês cell electrospinning), utilizada para produção de nanofibras contendo células viáveis. ${ }^{141} \mathrm{Kim}$ et al. desenvolveram scaffolds híbridos associando uma biotinta contendo células vivas de osteossarcoma humanas a NFs de policaprolatona (PCL). Os resultados mostraram que através do processo de C-ES foi possível obter uma carga de células com estrutura fibrosa que proporcionou alta viabilidade $\mathrm{e}$ proliferação celular. ${ }^{121}$ A técnica C-ES também foi empregada para obtenção de NFs contendo outros tipos de células como mioblastos, cardiomiócitos, osteoblastos, astrócitos humanos, neuroblastoma, células-tronco adiposas, entre outras. ${ }^{141,142}$ As NFs desenvolvidas para aplicação em engenharia de tecidos podem ainda ser utilizadas de forma associada para liberação de fármacos em locais específicos.

Métodos de carreamento e entrega de medicamentos utilizados como substitutivos aos métodos convencionais vêm despertando interesse na indústria farmacêutica. Partindo do princípio de que a taxa de dissolução de um fármaco aumenta com o aumento da área superficial, estudos envolvendo o uso da técnica de eletrofiação para o desenvolvimento de membranas para aplicação em curativos, invólucros para encapsulamento de fármacos/moléculas bioativas, entre outros sistemas, vêm sendo desenvolvidos. ${ }^{77,115,143-145}$ Diferentes estratégias podem ser empregadas para associação do fármaco às NFs, dentre elas pode-se destacar: incorporação na solução a ser eletrofiada, associação após o processo de eletrofiação, obtenção de estruturas do tipo core-shell ou encapsulamento usando nanopartículas ou nanoemulsões. ${ }^{113} \mathrm{Em}$ trabalho reportado por Yu et al. foram desenvolvidas NFs de três camadas para encapsulamento do antiflamatório cetoprofeno, utilizando aparato de eletrofiação triaxial. A imagem de MET da NF formada é apresentada na Figura 3b(i), assim como o resultado de liberação do fármaco em função do tempo (Figura 3b(ii)), o qual evidencia que a estrutura formada pelas NFs favorece liberação linear e constante do fármaco por até $20 \mathrm{~h} .{ }^{125}$

Nos últimos anos, tem-se observado também o aumento no número de pesquisas direcionadas para o desenvolvimento de novos curativos baseados em NFs. Nesse sentido, as NFs apresentam vários benefícios em relação a aplicação, incluindo porosidade ajustável, flexibilidade adequada para aplicações tópicas (pele), elevada razão área superficial/volume, capacidade de mimetizar a matriz extracelular do tecido e o controle na liberação de agentes bioativos que desempenham papel importante no processo de cicatrização de feridas. ${ }^{146}$ Através de um sistema de jato duplo, Hu e colaboradores desenvolveram NFs estruturadas em múltiplas camadas formadas pelos polímeros alginato e policaprolactona (PCL) carregadas com o fármaco ciprofloxacina para aplicação como curativo de feridas. ${ }^{123}$ Em outro trabalho, Ren et al. desenvolveram curativos inteligentes baseados em NFs alinhadas a fim de mimetizar a matriz extracelular do local alvo de aplicação. As NFs foram formadas utilizando o polímero poliácido láctico (PLLA) e nanopartículas de sílica mesoporosa contendo o fármaco dimetilglioxima. Testes in (a)

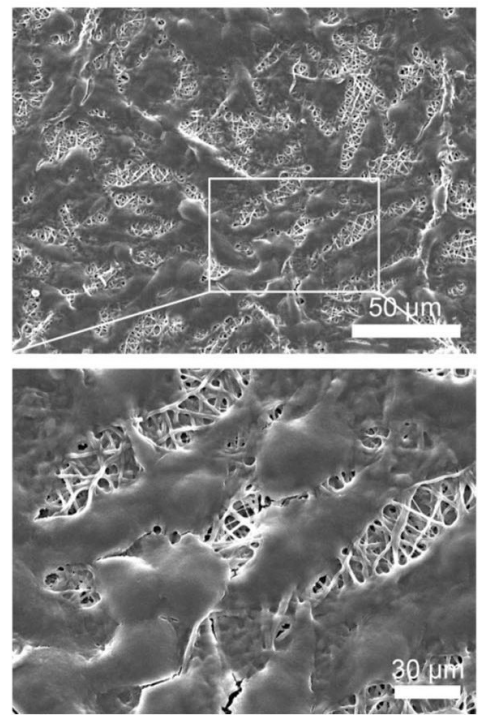

(b)

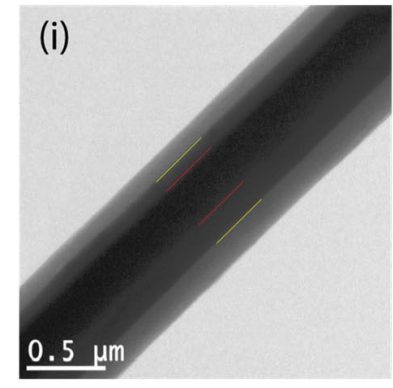

(ii)

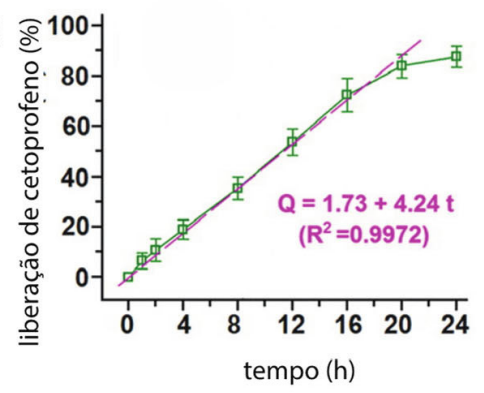

(c)

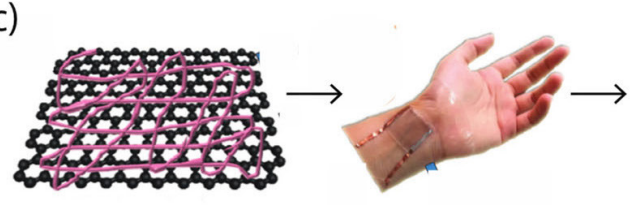

NFs de PAN sobre filme de grafeno

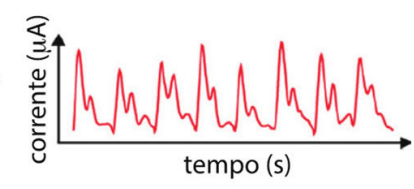

Aplicação na detecção de pulsos

Figura 3. (a) Imagens de MEV evidenciando a proliferação de células endoteliais sobre scaffolds formados por NFs de colágeno:quitosana:P(LLA-CL) na proporção 60:15:25. Reproduzida com permissão da referência 118. Copyright 2013 John Wiley \& Sons. (b) (i) Imagem de TEM das NFs triaxiais e (ii) gráfico de liberação do cetoprofeno em função do tempo. Adaptada com permissão da referência 125. Copyright 2015 American Chemical Society. (c) Esquema demonstrando o desenvolvimento e funcionamento do sensor de pulso (pressão) arterial formados por NFs de PAN sob filmes de grafeno. Adaptada com permissão da referência 129. Copyright 2019 American Chemical Society 
vivo demonstraram que os curativos promoveram a cicatrização do tecido através da proliferação celular, melhorando a vascularização, reparação do epitélio, auxiliando a produção de colágeno e reduzindo a inflamação em feridas de diabéticos, configurando um material promissor para a rápida cicatrização de feridas crônicas e úlceras diabéticas. ${ }^{122}$

NFs também vem sendo empregadas para a produção dos chamados tecidos inteligentes (do inglês, e-textiles) ${ }^{147} \mathrm{O}$ termo tecido inteligente refere-se a uma ampla gama de produtos têxteis, como fibras, filamentos e fios, na forma de malha tecida ou não tecida, que atuam como componentes eletrônicos fazendo interface entre o ambiente e os usuários. ${ }^{148}$ Esses materiais desempenham um papel importante no âmbito da Internet das Coisas (IoT, do inglês Internet of Things), especificamente no que diz respeito ao desenvolvimento de dispositivos eletrônicos vestíveis (wearable electronic system). Tais dispositivos vêm sendo desenvolvidos com tecnologias que trazem benefício e funcionalidade para os usuários podendo conduzir energia, comunicar-se com outros dispositivos ou funcionar como sistemas sensores auto-alimentados (self-powered). ${ }^{149,150}$ No que diz respeito à produção dos dispositivos eletrônicos vestíveis, NFs contendo materiais condutores vem sendo desenvolvidas a fim de conferir propriedades elétricas ao material final. ${ }^{14,149}$ Nesse cenário, NFs condutoras vêm sendo amplamente utilizadas como nanogeradores (NGs) de energia elétrica, sendo capazes de converter energia mecânica através da torção, dobra e alongamento do tecido (provenientes do movimento corporal) sem perda significante da sua performance. ${ }^{148}$ Os NGs mais frequentemente reportados são os baseados em efeitos triboelétrico ${ }^{151}$ e piezoelétrico. ${ }^{152}$ Além desses, sensores/NGs com mecanismos capacitivos ${ }^{127,133}$ e de transistor ${ }^{153}$ são também reportados. O sinal elétrico gerado em NGs é frequentemente utilizado para fornecer energia sustentável para os dispositivos vestíveis e/ou para o sensoriamento de sinais fisiológicos. ${ }^{154}$ Nesse sentido, vários trabalhos são encontrados na literatura reportando desenvolvimento de sensores vestíveis baseados em NFs que atuam como NGs auto-alimentados para detecção e monitoramento de movimentos do corpo (sensores de pressão/estímulo) e sinais fisiológicos visando cuidados com a saúde. ${ }^{155,156}$

Wang et al. desenvolveram um sensor de pressão vestível flexível utilizando NFs de fibroína de seda carbonizadas e filmes não estruturados de polidimetilsiloxano (PDMS). O dispositivo obtido apresentou alta sensibilidade, possibilitando a demonstração do monitoramento de sinais fisiológicos coletados a partir do pulso arterial, da veia jugular, da respiração (normal e após exercícios) e do som da fala. Além disso, quando acoplado aos diferentes dedos da mão, o sensor foi capaz de diferenciar a intensidade de força utilizada para pegar objetos. ${ }^{128}$ You et al. desenvolveram um sensor capacitivo utilizando um compósito de fios, no qual um fio de algodão recoberto com níquel foi revestido por NFs de poliuretano dopadas com grafeno. $\mathrm{O}$ fio recoberto com níquel atuou como eletrodo condutor e o recobrimento deste com as NFs promoveram a formação de uma camada dielétrica. $\mathrm{O}$ sensor formado se mostrou adequado para reconhecimento de voz, monitoramento do fluxo de ar (respiração) e dos movimentos musculares dos dedos e punhos. ${ }^{133}$ Ren et al. desenvolveram sensores de pressão transparentes e flexíveis através da deposição de NFs de PAN sob filmes de grafeno. O dispositivo mostrou-se eficaz na amplificação de sinais coletados do pulso arterial. ${ }^{129} \mathrm{Na}$ Figura 3c é apresentado o esquema de produção do dispositivo, aplicação em voluntário e medida de corrente por tempo gerada a partir da pressão/pulso arterial. Além dos sensores de pressão (estímulo) para monitoramento de sinais fisiológicos, são encontrados na literatura trabalhos utilizando NFs para o desenvolvimento de (bio) sensores químicos vestíveis para detecção de analitos de interesse da área da saúde. ${ }^{136}$

\section{Aplicações ambientais}

Os poluentes ambientais representam uma ameaça crescente para a saúde humana e para os ecossistemas do planeta. Além da emissão/liberação desenfreada de poluentes (sólidos, líquidos e gasosos) no meio ambiente, a carência por tratamentos efetivos para remoção e degradação destes poluentes é um problema para o futuro sustentável do planeta. Sendo assim, pesquisas que busquem a remediação destes poluentes são de grande importância e têm recebido bastante atenção nos últimos anos. ${ }^{58,157-159}$ Nesse sentido, as mantas de NFs apresentam-se como potenciais materiais para aplicação em processos de filtração/adsorção e também, como plataforma para degradação destes poluentes por meio de processos catalíticos. ${ }^{58,160} \mathrm{~A}$ estrutura altamente porosa facilita o transporte de gases e líquidos, enquanto as dimensões desses poros asseguram a retenção dos poluentes e contaminantes. De fato, mantas de NFs, particularmente aquelas com funcionalização de superfície, têm sido ativamente exploradas como filtros para a remoção de poluentes, como material particulado, metais pesados e moléculas orgânicas, em amostras de ar e águas poluídas. ${ }^{58,157,158,161,162}$ Os resultados reportados na literatura indicam que as membranas baseadas em NFs eletrofiadas apresentam desempenho superior na remoção de poluentes de forma rápida e eficaz e com bons índices de reuso. Nesse sentido, Xiong e colaboradores reportaram, recentemente, a aplicação de NFs hierárquicas contendo nanopartículas de $\mathrm{SiO}_{2}$ para separação de óleo-água por processo de filtração. ${ }^{163}$ Os resultados apresentados demonstraram que o controle dos poros, inter- e intrafibra das membranas, contribuiu para a separação e remoção de óleo em sistemas óleo-água, de acordo com a viscosidade do óleo. Os autores descreveram ainda que, devido à diferença de área superficial, estrutura dos poros e hidrofobicidade das nanopartículas de $\mathrm{SiO}_{2}, \mathrm{O}$ óleo foi transferido da camada externa das mantas para as camadas internas onde então permaneceu adsorvido às NFs por forças de van der Waals. Em outro trabalho, Liu e colaboradores mostraram a influência da polaridade das mantas de NFs poliméricas no desempenho de filtração de material particulado (mistura de partículas pequenas e microgotas suspensas no ar e que carregam componentes tanto orgânicos quanto inorgânicos). ${ }^{164}$ Os autores produziram filtros nanofibrosos transparentes com características semelhantes variandose apenas a composição e, com isso, a polaridade da superfície das fibras. As NFs foram obtidas a partir dos polímeros PAN, PVP, PVA, poliestireno (PS) e polipropileno (PP), os quais apresentam momento de dipolo 3,6;2,3;1,2; 0,7 e 0,6 D, respectivamente. A filtração de ar contendo material particulado foi realizada com todas as membranas e, a maior eficiência (>95\%), foi observada para a manta formada por NFs de PAN, devido às características estruturais inerentes das NFs e, principalmente, à suas características de superfície. Os autores demonstraram assim o potencial do uso da técnica de eletrofiação para o desenvolvimento de filtros nanoestruturados em máscaras e filtros HEPA (do inglês, High Efficiency Particulate Arrestance). Recentemente, Mercante et al. explorou a técnica de eletrofiação para a obtenção de nanofibras flexíveis e autossustentáveis de $\mathrm{SiO}_{2} / \mathrm{TiO}_{2}$ funcionalizadas com dissulfeto de molibdênio $\left(\mathrm{MoS}_{2}\right){ }^{165}$ As membranas inorgânicas funcionalizadas $\left(\mathrm{SiO}_{2} / \mathrm{TiO}_{2}-\mathrm{MoS}_{2}\right)$ foram empregadas para remoção de íon de $\mathrm{Pb}$ (II) em água e apresentaram uma alta capacidade de adsorção removendo até $90 \%$ dos íons em solução. É importante ressaltar que a integridade das membranas foi mantida durante todo o processo de filtração possibilitando a reutilização com perda de menos de $10 \%$ na capacidade de filtração após quatro ciclos. A Tabela 3 apresenta um comparativo de alguns trabalhos recentes encontrados na literatura que reportam o emprego de NFs como membrana para filtração e adsorção de contaminantes em amostras de ar e água. O intuito dessa comparação é trazer para 
o leitor uma representação dos materiais e aplicações que mais vêm sendo explorados.

Outra estratégia promissora no contexto de aplicações ambientais é a utilização de NFs como plataforma para degradação dos poluentes por fotocátalise. ${ }^{58,158,161,162}$ Nesse cenário, as membranas compostas por NFs à base de óxidos metálicos semicondutores ganham especial destaque. ${ }^{38}$ Uma das fases mais empregadas para obtenção de NFs com potencial aplicação em processos de fotocatálise é o $\mathrm{TiO}_{2}$, sendo merecedor de um artigo de revisão abordando a importância desse material em processos fotocatalíticos. ${ }^{174}$ Além do $\mathrm{TiO}_{2}, \mathrm{NFs}$ baseadas em outros materiais como: $\mathrm{ZnO}, \mathrm{NiO}, \mathrm{V}_{2} \mathrm{O}_{5}$ e $\mathrm{Fe}_{2} \mathrm{O}_{3}$ também vêm sendo utilizadas para degradação de poluentes ambientais por fotocatálise. ${ }^{101,175,176}$ Apesar dos óxidos metálicos semicondutores serem os mais tradicionais para essas aplicações, nos últimos anos, novos materiais também têm demonstrado alto potencial para atuarem tanto em conjunto com os óxidos metálicos quanto isoladamente. Zhong e colaboradores, por exemplo, reportaram o uso de NFs de carbono funcionalizadas com nanoestruturas de sulfeto de estanho $\left(\mathrm{CNF} @ \mathrm{SnS}_{2}\right)$ para fotodegradação de $\mathrm{Cr}(\mathrm{VI}) .{ }^{177}$ As NFs demonstraram eficiência fotocatalítica para degradação de altas concentrações de $\mathrm{Cr}(\mathrm{VI})$ em água de reuso chegando à degradação completa em 90 minutos, como demonstrado no gráfico da Figura 4a(i). Nanoestruturas de $\mathrm{SnS}_{2}$ são conhecidas por seu alto desempenho em aplicações fotocatalíticas, porém a nova arquitetura apresentada pelos autores apresentou desempenho superior quando comparada aos constituintes isolados. Os autores atribuíram tal desempenho à cadeia tridimensional de poros e também à estrutura hierárquica formada pela ancoragem das nanoestruturas de $\mathrm{SnS}_{2}$ à superfície das NFs de carbono (Figura 4a(ii)). Assim, o efeito sinérgico contribui para o desempenho fotocatalítico da membrana resultando em $100 \%$ de degradação do $\mathrm{Cr}(\mathrm{VI})$, além de excelente estabilidade ao longo de seguidos ciclos de reuso (Figura 4a(iii)). Considerando ainda o emprego de materiais alternativos aos óxidos semicondutores, Han e colaboradores reportaram recentemente a obtenção de NFs multifuncionais compostas por PAN, óxido de grafeno reduzido-poliamidoxima (rGO- $g$-PAO) funcionalizadas com íons $\mathrm{Ag}^{+}$para fotodegradação de diferentes corantes orgânicos (Figura 4b). ${ }^{178}$ Os autores prepararam diferentes nanoestruturas variando-se a concentração de rGO-g-PAO e observaram uma melhor performance para as NFs contendo $15 \%$ de rGO- $g$-PAO (amostra CNFM4-7) em massa com relação à massa total das NFs (Figura 4b(ii)). O mecanismo de ação dessa membrana foi descrito como um processo em que fotoelétrons são gerados por irradiação de luz dando origem ao par elétron-buraco promovendo a absorção de luz e, consequente, atividade fotocatalítica (Figura $4 \mathrm{~b}$ (iii)). Os autores reportaram ainda a atividade bactericida devido à presença do par $\mathrm{Ag}^{+} / \mathrm{Ag}^{0}$, conferindo caráter multifuncional à membrana. Vale destacar que a maior parte das membranas citadas até aqui, para a remoção e remediação de poluentes, apresentam boas propriedades mecânicas, sendo resistentes ao manuseio e permitindo alguns ciclos de reutilização após aplicação, como evidenciado nos dados apresentados na Tabela 3.

\section{Aplicações em (bio)sensores químicos}

Como mencionado anteriormente, as membranas formadas por NFs apresentam estruturas típicas em rede $3 D$ com elevada área superficial e alta porosidade, características altamente desejáveis para o desenvolvimento de (bio)sensores com maior sensibilidade e menor limite de detecção. ${ }^{33,179}$ Além disso, a estrutura $1 D$ de NFs condutoras fornecem caminhos encurtados para a transferência de elétrons, facilitando assim a interação do analito ao longo do eixo longitudinal das nanofibras melhorando, portanto, o desempenho do sensor. ${ }^{180}$ Nesse cenário, as NFs têm sido amplamente exploradas para aplicação em (bio)sensores químicos visando a detecção de gases tóxicos $\left(\mathrm{NH}_{3}, \mathrm{NO}_{\mathrm{x}}\right.$, $\mathrm{CO}, \mathrm{CH}_{4}$, etc) ${ }^{30,114}$ explosivos, ${ }^{179,181}$ poluentes emergentes (hormônios, fármacos, corantes orgânicos, pesticidas e inseticidas), ${ }^{31,179,182,183}$ metais pesados (Cd(VI), $\mathrm{Cr}(\mathrm{VI}), \mathrm{Pb}(\mathrm{II}), \mathrm{Hg}(\mathrm{II})),{ }^{32,184,185}$ analitos de interesse biomédico, ${ }^{156,186,187}$ entre outros.

Os trabalhos encontrados na literatura que tratam de (bio) sensores baseados em NFs empregam, em sua maioria, métodos de

Tabela 3. Exemplos de aplicação de NFs como membrana para filtração e adsorção de poluentes

\begin{tabular}{|c|c|c|c|c|c|c|}
\hline Material & Tipo de NF & Aplicação & Capacidade de adsorção $(\mathrm{g} / \mathrm{g})$ & $\begin{array}{c}\text { Eficiência de } \\
\text { filtração/adsorção (\%) }\end{array}$ & $\begin{array}{c}\text { Número de } \\
\text { ciclos de reuso }\end{array}$ & Ref \\
\hline PS-CA/PS-CA-HSiO ${ }_{2}{ }^{a}$ & Híbrida & Separação/adsorção de óleo & 164 & 99 & 3 & 163 \\
\hline $\mathrm{PLA} / \gamma-\mathrm{Fe}_{2} \mathrm{O}_{3}$ & Híbrida & Separação/adsorção de óleo & 268,6 & - & 11 & 78 \\
\hline $\mathrm{PEI}-\mathrm{SiO}_{2}{ }^{\mathrm{b}}$ & Híbrida & $\begin{array}{l}\text { Filtração de partículas } \\
\text { em ar }\end{array}$ & - & 99,99 & - & 166 \\
\hline PA6/TPP & Compósita & $\begin{array}{l}\text { Filtração de material parti- } \\
\text { culado em ar }\end{array}$ & - & $>99,50$ & - & 167 \\
\hline $\mathrm{PAN} / \mathrm{SiO}_{2}$ & Híbrida & $\begin{array}{l}\text { Adsorção de compostos } \\
\text { voláteis orgânicos }\end{array}$ & $\begin{array}{l}\text { 1,841 (clorofórmio); } 1,084 \text { (ácido } \\
\text { fórmico); 0,835 (metanol) }\end{array}$ & - & 10 & 168 \\
\hline SPES $^{d}$ & Polimérica & $\begin{array}{l}\text { Adsorção de } \mathrm{Pb} \text { (II) e azul } \\
\text { de metileno }\end{array}$ & 0,006 e 0,007 & $>99$ & 3 & 169 \\
\hline $\mathrm{SiO}_{2} / \mathrm{TiO}_{2}-\mathrm{MoS}_{2}$ & Compósita & Adsorção de $\mathrm{Pb}(\mathrm{II})$ & 0,741 & 96 & 5 & 165 \\
\hline PANADC $^{e}$ & Polimérica & Adsorção de Fe(III) & 0,014 & - & - & 170 \\
\hline $\mathrm{SiO}_{2}-\mathrm{MgO}$ & Compósita & Adsorção de $\mathrm{Pb}(\mathrm{II})$ e $\mathrm{Cu}(\mathrm{II})$ & 0,788 e 0,493 & 100 & 3 & 96 \\
\hline CPANM $^{\mathrm{f}}$ & Carbono & Adsorção de $\mathrm{Cr}(\mathrm{VI})$ & 0,261 & 97,6 & 5 & 171 \\
\hline $\mathrm{PAN} / \mathrm{Ag}_{3} \mathrm{VO}_{4} / \mathrm{TiO}_{2}$ & Híbrida & $\begin{array}{l}\text { Adsorção do corante azul } \\
\text { de metileno }\end{array}$ & 0,155 & 95 & 6 & 172 \\
\hline $\mathrm{RGO} / \mathrm{TiO}_{2} / \mathrm{PANCMA}^{\mathrm{g}}$ & Híbrida & $\begin{array}{c}\text { Adsorção dos corantes } \\
\text { verde de malaquita e verde } \\
\text { de leucomalaquita }\end{array}$ & - & 90,6 e 93,7 & 13 & 173 \\
\hline
\end{tabular}

${ }^{\mathrm{a}} \mathrm{CA}$ - acetato de celulose, $\mathrm{HSiO}_{2}$ - nanopartículas hidrofóbicas de sílica; ${ }^{\mathrm{b}} \mathrm{PEI}$ - polieterimida; ${ }^{\mathrm{CPTT}}$ - trifenil fosfato; ${ }^{\mathrm{d} S P E S}$ - polietersulfona; $\mathrm{ePANADC}$ poli(acrilonitrila-co-ácido acrolico-co-diamino-piridina-co-curmarina); ${ }^{\mathrm{f}} \mathrm{CPANM}$ - Membrana de NFs de carbono obtidas a partir da carbonização de NFs de quitosana/PEO; ${ }^{g} \mathrm{RGO}$ - óxido de grafeno reduzido, PANCMA - poli(acrilonitrila-co-ácido maleico). 
(a) (i)

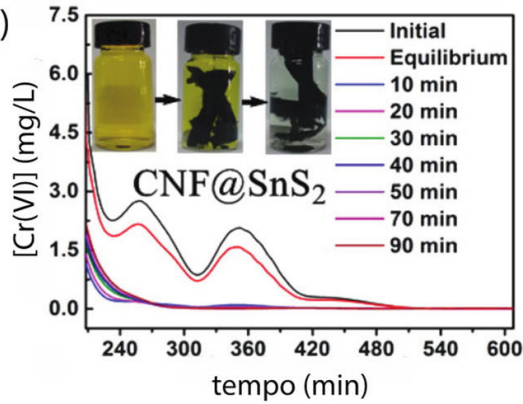

(ii)

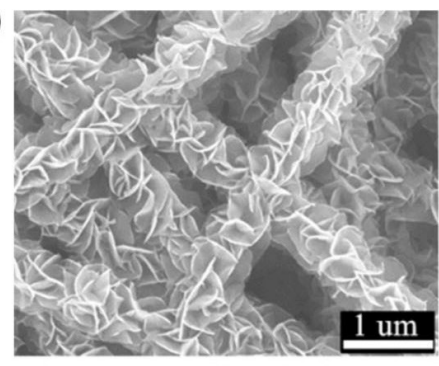

(iii)

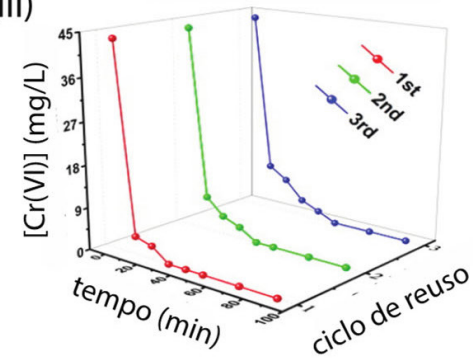

(iii)

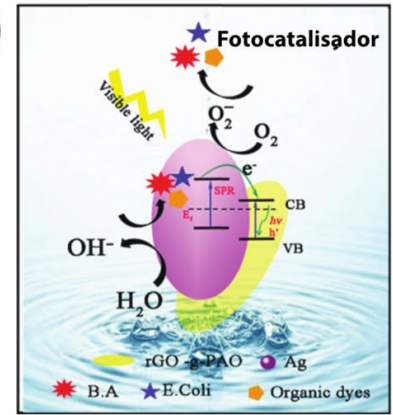

(b) (i)

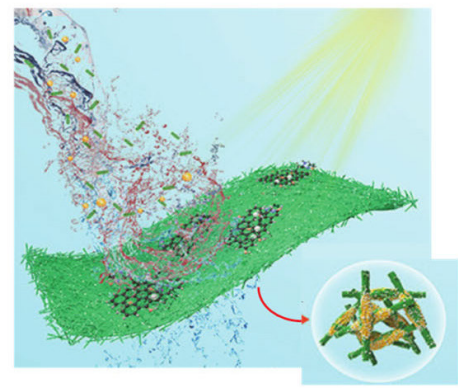

(ii)

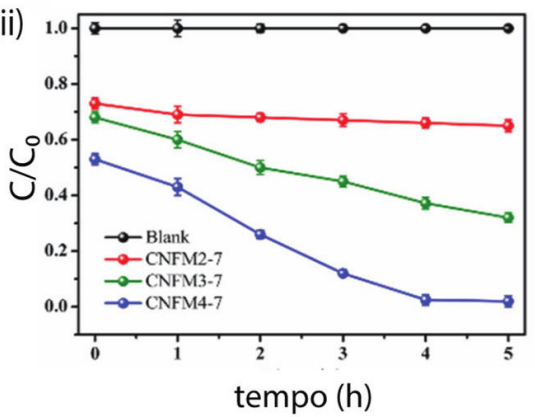

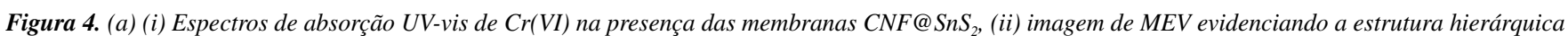
das NFs de CNF@SnS $S_{2}$ e (iii) performance fotocatalítica após três ciclos de degradação. Adaptada com permissão da referência 177. Copyright 2016 American Chemical Society. (b) (i) Representação esquemática da manta em processo de filtração e sua microestrutura, (ii) fotodegradação do ácido benzoico (BA) quando em contato com a manta e sob irradiação UV, (iii) representação do mecanismo de fotodegradação proposto. Adaptada com permissão da referência 178. Copyright 2019 American Chemical Society

transdução resistivo, óptico e eletroquímico, também conhecidos como sensores elétricos, ópticos e eletroquímicos, respectivamente. É importante destacar que cada um desses tipos de sensores possui uma teoria referente à cada método de transdução, havendo extensa literatura dedicada à compreensão dos mecanismos de atuação destes sensores. Sendo assim, a seguir abordaremos em mais detalhes alguns exemplos recentes referentes à utilização de NFs como plataforma sensorial para obtenção destes dispositivos. A Tabela 4 apresenta um comparativo de alguns dos trabalhos mais recentes publicados na literatura que reportam sensores compostos por NFs para detecção de diferentes analitos com seus respectivos métodos de transdução e limites de detecção.

Os sensores resistivos operam com base na variação da resistência elétrica ao serem expostos ao analito de interesse. Tais variações ocorrem como resultado de interações químicas entre o analito e a camada sensorial, neste caso, formada pelas NFs. ${ }^{13}$ Assim, o desempenho do sensor vai depender da morfologia e composição do material, além de outros parâmetros como temperatura operacional e da configuração do sensor. Nesse sentido, as NFs cerâmicas ganham destaque por serem termicamente estáveis possibilitando seu uso em sistemas de sensoriamento que requerem operação em altas temperaturas. ${ }^{204}$ Adicionalmente, estudos têm demonstrado melhor desempenho dos materiais semicondutores na forma de NFs cerâmicas em comparação com material de geometria tradicional (filmes finos e nanopartículas) da mesma composição. ${ }^{30}$

NFs poliméricas contendo polímeros condutores em sua composição também vêm sendo empregadas como plataforma sensorial em sensores resistivos. ${ }^{205}$ Tais polímeros são estruturas orgânicas com condutividade elétrica intrínseca, devido à presença de elétrons $\pi$-conjugados ao longo da cadeia polimérica ${ }^{69} \mathrm{~A}$ alteração na condutividade desses polímeros quando expostos à diferentes analitos é explicada na literatura por cinco diferentes mecanismos: (i) forma como o analito afeta a transferência de carga entre as nanofibras e o eletrodo; (ii) criação/eliminação de portadores de carga (reações de oxidação/redução na cadeia polimérica); (iii) alteração da mobilidade dos portadores de carga na cadeia polimérica devido à interação do analito com os portadores de carga livres do polímero; (iv) interação do analito com contra íons da camada sensorial, alterando assim a mobilidade dos portadores de carga na cadeia polimérica; (v) modulação da resistência do polímero condutor pela interação com o analito que afeta a transferência de carga entre cadeias. ${ }^{205} \mathrm{Os}$ polímeros conjugados mais empregados em sensores são a PANI, o polipirrol (PPy) e o poli(3,4-etilenodioxitiofeno) (PEDOT), pois apresentam vantagens como excelentes propriedades elétricas, fácil procedimento de síntese, flexibilidade e estabilidade ambiental. ${ }^{205}$ Além do uso dos materiais citados de forma isolada, o uso de NFs compósitas/híbridas confere um melhor desempenho sensorial devido ao efeito sinérgico entre os materiais constituintes..$^{30,76,189,206}$ Nesse sentido, Hou e colaboradores ${ }^{191}$ relataram a obtenção de mantas de NFs autossustentáveis com composição ternária contendo NFs de carbono (CNF), dissulfeto de molibdênio $\left(\mathrm{MoS}_{2}\right)$ e dissulfeto de cobalto $\left(\mathrm{CoS}_{2}\right)$ para detecção seletiva de NO (Figura 5a(i)). As NFs ternárias hierárquicas $\left(\mathrm{CNF} / \mathrm{CoS}_{2} / \mathrm{MoS}_{2}\right)$ exibiram bom desempenho de detecção, notável seletividade ao NO e excelente repetibilidade à temperatura ambiente. Além do excelente desempenho para a detecção de NO, as NFs ternárias também apresentaram propriedades mecânicas que possibilitaram o manuseio e até mesmo dobras sem alterar ou influenciar as respostas dos sensores, como ilustrado na Figura 5a(ii). Os autores destacaram que a incorporação das nanofolhas de $\mathrm{MoS}_{2}$ e das nanopartículas de $\mathrm{CoS}_{2}$ às CNFs aumentou substancialmente a seletividade e a resposta do sensor ao NO devido à sinergia entre os constituintes, o que pôde ser comprovado por estudos teóricos do mecanismo envolvido. Além do estudo teórico, NFs de carbono binárias $\left(\mathrm{CNFs} / \mathrm{CoS}_{2}\right.$ e $\left.\mathrm{CNFs} / \mathrm{MoS}_{2}\right)$ também foram fabricadas e testadas comprovando experimentalmente a diferença de desempenho entre os materiais (Figura 5a(iii)).

Os sensores ópticos operam com base na variação das características ópticas do material empregado como camada sensorial. De modo geral, os sensores ópticos operam em função da absorção ou emissão de energia luminosa. ${ }^{32}$ Os sensores 
Tabela 4. Exemplos de aplicações de NFs para sensoriamento de diferentes analitos

\begin{tabular}{|c|c|c|c|c|c|}
\hline Material & Tipo de NF & Método de transdução & Analito & Limite de detecção (ppm) & Ref. \\
\hline $\mathrm{Co}_{3} \mathrm{O}_{4}$ & Cerâmica & Resistivo & Acetona & 5 & 99 \\
\hline $\mathrm{PANI} / \mathrm{ZnO} / \mathrm{PEO}$ & Híbrida & Resistivo & Gás liquefeito de petróleo & 1000 & 188 \\
\hline $\mathrm{ZnO} @ \mathrm{In}_{2} \mathrm{O}_{3}$ & Cerâmica & Resistivo & Etanol & 5 & 108 \\
\hline $\mathrm{ZnO}-\mathrm{SnO}_{2}$ & Cerâmica & Resistivo & Etanol & 5 & 98 \\
\hline $\mathrm{In}_{2} \mathrm{O}_{3}-\mathrm{rGO}$ & Híbrida & Resistivo & Etanol & 0,044 & 189 \\
\hline $\mathrm{ZnO} / \mathrm{PSS}^{\mathrm{a}}$ & Híbrida & Resistivo & $\mathrm{NH}_{3}$ & 3,22 & 190 \\
\hline $\mathrm{CNFs} / \mathrm{CoS}_{2} / \mathrm{MoS}_{2}{ }^{\mathrm{b}}$ & Híbrida & Resistivo & NO & 1 & 191 \\
\hline $\mathrm{SnO}_{2}$ dopado com Ni & Cerâmica & Resistivo & $\mathrm{NO}_{2}$ & 20 & 192 \\
\hline PLA/PEO/espirulina & Compósita & Colorimétrico & $\mathrm{pH}$ & - & 193 \\
\hline $\mathrm{PDA} / \mathrm{PAN}^{\mathrm{c}}$ & Compósita & Colorimétrico & $\mathrm{Pb}(\mathrm{II})$ & 0,1 & 184 \\
\hline PdO@ZnO/PAN & Híbrida & Colorimétrico & $\mathrm{H}_{2}$ & $<1000$ & 194 \\
\hline cDNA@Au-G-CA ${ }^{\mathrm{d}}$ & Híbrida & Colorimétrico & Canamicina (antibiótico) & 0,0012 & 195 \\
\hline PVP_Eu(III) & Polimérica & Luminescente & $\mathrm{NH}_{3}$ & 4,7 & 196 \\
\hline PMMA_PFO & Compósita & Luminescente & Clorofórmio & 15,4 & 197 \\
\hline Porfirina de Zinco/PI & Polimérica & Luminescente & Piridina & 0,041 & 198 \\
\hline Poli(MMA-co-Sal) ${ }^{\mathrm{f}}$ & Polimérica & Luminescente & $\mathrm{Zn}(\mathrm{II})$ & 0,013 & 199 \\
\hline PVA/GQDs & Híbrida & Luminescente & Glicose & 2,16 & 200 \\
\hline $\mathrm{PA} 6 / \mathrm{PPy} / \mathrm{ZnO} /$ urease & Híbrida & Impedimétrico & Urea & 0,011 & 64 \\
\hline PA6/PPy/rGO & Híbrida & Potenciométrico & Malation (pesticida) & 0,0008 & 201 \\
\hline PCL/GO & Híbrida & Potenciométrico & Bisphenol A & 0,005 & 183 \\
\hline $\mathrm{Co}_{3} \mathrm{O}_{4}-\mathrm{CNF}$ & Híbrida & Amperométrico & L-Triptofano & 0,0004 & 202 \\
\hline PA6/PANI_ZnO & Híbrida & Amperométrico & Hidrazina & 0,011 & 203 \\
\hline $\mathrm{NiMoO}_{4} / \mathrm{CNF}$ & Híbrida & Amperométrico & Glicose & 0,009 & 95 \\
\hline CuO-NFs/PIGE ${ }^{g}$ & Cerâmica & Amperométrico & Glicose & 0,07 & 94 \\
\hline $\mathrm{CuO} / \mathrm{PANI}$ & Híbrida & Amperométrico & Glicose e $\mathrm{H}_{2} \mathrm{O}_{2}$ & 0,08 e 0,004 & 186 \\
\hline
\end{tabular}

${ }^{\mathrm{a} P S S}$ - poliestirenosulfonato; ${ }^{\mathrm{b}} \mathrm{CNFs}$ - NFs de carbono; ${ }^{\mathrm{PDA}}$ - polidiacetileno; ${ }_{\mathrm{d}}^{\mathrm{c} D N A} @ \mathrm{Au}$ - aptamero da canamicina conjugado a nanopartículas de ouro,

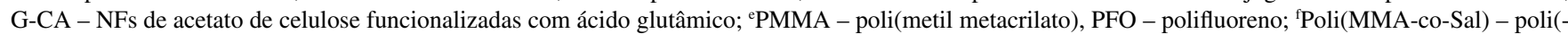

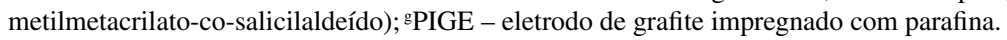

(a)

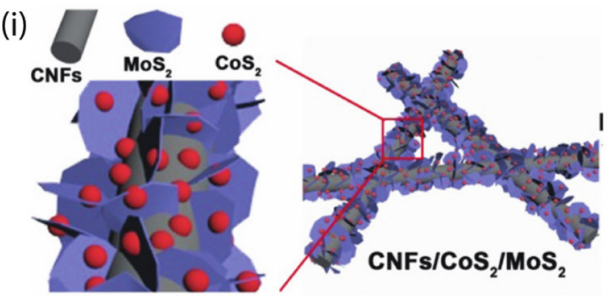

(b)

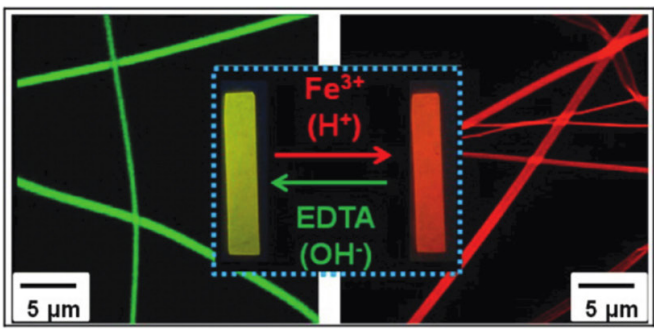

(ii)

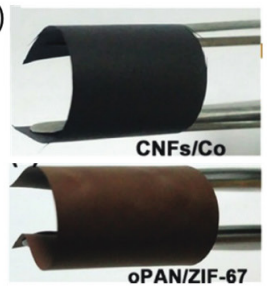

(c)

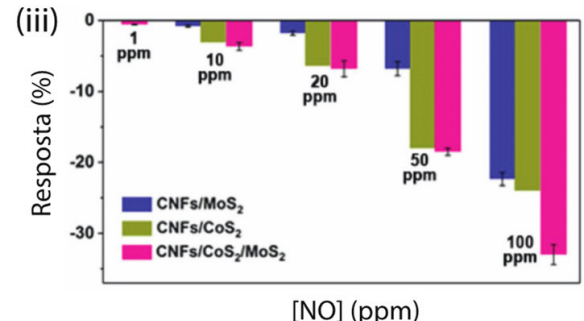

Eletrodo de FTO modifcado com as NFs de PA6/PPy/ZnO/urease
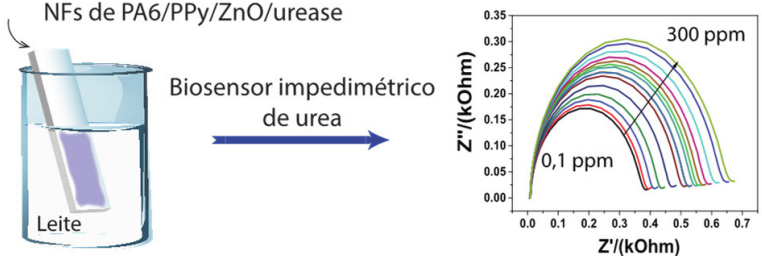

Biosensor impedimétrico de urea Z'/(kOhm)

Figura 5. (a) (i) Ilustração representativa da estrutura ternária das nanofibras de CNFs/ $\mathrm{CoS}_{2} / \mathrm{MoS}_{2}$, (ii) fotografia digital representando a flexibilidade da manta antes e após a calcinação e (iii) resposta elétrica seletiva do sensor na presença de diferentes concentrações de NO. Adaptada com permissão da referência 191. Copyright 2020 American Chemical Society. (b) Esquema evidenciando a mudança da cor de emissão de NFs multifuncionais em função do pH e da concentração de Fe(III). Adaptada com permissão da referência 207. Copyright 2015 American Chemical Society. (c) Representação esquemática de operação do biossensor baseado em NFs de PA6/PPy/ZnO/urease para detecção de ureia em amostras de leite. Adaptada com permissão da referência 64. Copyright 2018 Elsevier 
operantes em função da absorção, também chamados de sensores colorimétricos, tem como resposta a mudança de coloração, ou seja, a faixa de luz visível absorvida pelo material sofre alteração após interação com o analito. ${ }^{208} \mathrm{~A}$ mudança de cor do cromóforo pode ser identificada a olho nu, tornando esse método de fácil operação e muito conveniente para miniaturização, por geralmente não necessitar de instrumentação avançada. ${ }^{32}$ Polímeros conjugados são muito empregados para o desenvolvimento de sensores colorimétricos por apresentarem mudanças de cor sob influência de estímulos externos como calor, reações de oxidação ou redução, processos de dopagem e desdopagem ou interações ligante-receptor, possibilitando a detecção de diferentes analitos. ${ }^{205,208} \mathrm{NFs}$ contendo corantes orgânicos e nanopartículas metálicas também vem sendo empregadas para obtenção de sensores colorimétricos. ${ }^{208}$ Nesse aspecto, Hwang e colaboradores ${ }^{194}$ apresentaram recentemente a obtenção de um sensor colorimétrico para detecção de $\mathrm{H}_{2}$. A plataforma desenvolvida, composta por NFs de PAN funcionalizadas com nanopartículas de $\mathrm{PdO}$ e $\mathrm{ZnO}$, apresentou alteração da coloração em apenas 2 minutos após exposição ao gás passando da cor marrom para cinza. Os autores demonstraram ainda a possibilidade de utilização dessas mantas como sensores vestíveis indicando alta potencialidade de aplicação comercial.

Nos sensores ópticos que operam com base na variação das características de emissão de luz do material, a resposta é dada em função da influência do analito nas propriedades de emissão do fluoróforo após ser excitado em um comprimento de onda definido. ${ }^{32}$ Para obtenção de sensores luminescentes, as principais estratégias utilizadas envolvem a utilização de polímeros e moléculas fluorescentes, corantes orgânicos e quantum dots. ${ }^{32,181}$ Xue e colaboradores, por exemplo, utilizaram como fluoróforo o complexo tetra-(pentafluorfenil)porfirina de Pd(II) (PdTFPP) para obtenção de um sensor de oxigênio para definir o nível de hipóxia de células tumorais. ${ }^{181}$ As NFs, com estrutura do tipo coreshell, foram desenvolvidas tendo no núcleo o complexo PdTFPP encapsulado pelo polímero policarbonato (PC) e externamente o polímero biocompatível PCL. As NFs formadas apresentaram intensa emissão luminescente em $673 \mathrm{~nm}$ e apresentaram elevada sensibilidade quando expostas à presença de oxigênio no ambiente das células tumorais. Em outro trabalho, NFs multifuncionais compostas por poli(2-hidroxietilmethcrilato- $\mathrm{Co}-\mathrm{N}$-metilolacrilamidaco-nitrobenzoxadiazolil) (poly(HEMA-co-NMA-co-NBD)) e derivado do corante rodamina exibiram resposta luminescente para pH e Fe(III) (Figura 5b). ${ }^{207}$ As NFs apresentaram mudança da cor de emissão, de verde para vermelho, quando expostas à soluções ácidas ou à soluções aquosas de Fe(III), como ilustrado na Figura 5b. Além disso, a plataforma sensorial apresentou boa reversibilidade indicando a capacidade de reutilização e potencialidade para aplicação em dispositivos de detecção multifuncional. Estratégias de funcionalização com mais de um composto opticamente ativo permitem ainda a obtenção de sensores duais, como reportado por Cho e colaboradores. ${ }^{209}$ Os autores observaram que alterações significativas na concentração dos íons $\mathrm{Cu}$ (II) e $\mathrm{Hg}$ (II) puderam ser facilmente identificadas por meio da alteração de cor de NFs de poli(2-hidroxietilmetacrilato-co- $N$-metilolacrilamida) (poli(HEMAco-NMA)) modificadas com o corante rodamina B (RhBN2) ou derivados de pireno (PyDAN2). A mesma plataforma sensorial ainda foi utilizada para determinação do pH através da investigação das propriedades luminescentes das NFs em diferentes meios.

NFs também vem sendo amplamente empregadas para o desenvolvimento de (bio)sensores eletroquímicos. ${ }^{179,187}$ De modo geral, a reação eletroquímica produz uma corrente quantificável, que pode ser explorada em métodos de detecção amperométrica, ${ }^{202}$ ou um potencial elétrico mensurável, através de métodos de detecção potenciométrica, ${ }^{210}$ ou ainda provoca variações na condutividade elétrica do meio, que pode ser mensurada através de método condutimétrico. ${ }^{192}$ Existem também outros tipos de detecção eletroquímica, como por exemplo, sensores impedimétricos, que tratam de variações na impedância eletroquímica ${ }^{64} \mathrm{Nesse}$ sentido, Migliorini e colaboradores desenvolveram um biosensor impedimétrico baseado em eletrodos de FTO (do inglês, fluorine doped tin oxide) modificados com nanofibras híbridas de PA6, PPy e nanopartículas de $\mathrm{ZnO}(\mathrm{PA} 6 / \mathrm{PPy} / \mathrm{ZnO}) .{ }^{64} \mathrm{Com}$ o objetivo de obter uma plataforma seletiva, os autores imobilizaram a enzima urease sob a superfície do eletrodo modificado. O eletrodo apresentou, além da seletividade, elevada sensibilidade para detecção de ureia em amostras de leite (Figura 5c).

Óxidos metálicos na forma de NFs também apresentam grande potencial para aplicação em sensoriamento eletroquímico, desempenhando um papel importante no monitoramento ambiental e diagnósticos biomédicos. ${ }^{94,185}$ Recentemente, NFs de $\mathrm{SnO}_{2}$ funcionalizadas com o anticorpo anti-atrazina foram empregadas como plataforma para detecção ultrassensível e seletiva do herbicida atrazina em águas residuais. ${ }^{211} \mathrm{O}$ imunossensor proposto apresentou uma ampla faixa de detecção $\left(1 \mu \mathrm{mol} \mathrm{L}-1-1 \mathrm{zmol} \mathrm{L}^{-1}\right)$ e um limite de detecção de $0,9 \mathrm{zmol} \mathrm{L}^{-1}\left(0,9 \times 10^{-21} \mathrm{~mol} \mathrm{~L}^{-1}\right)$. Os autores atribuem a alta performance do biossensor $\grave{a}$ natureza semicondutora do $\mathrm{SnO}_{2}$ e ao fato das NFs introduzirem heterogeneidade à superfície do eletrodo de trabalho. Como resultado, mesmo uma pequena alteração interface eletrodo-eletrólito, que pode ter sido causada pela adsorção de algumas moléculas de analito, é capaz de alterar a densidade de corrente, tornando possível a detecção do analito em concentrações tão baixas.

Além dos polímeros condutores e óxidos semicondutores, nanomateriais a base de carbono, como os derivados do grafeno e nanotubos de carbono, também têm demonstrado grande potencial para aplicação em sensores eletroquímicos. ${ }^{31,212}$ Pavinatto e colaboradores, por exemplo, reportaram o uso de NFs de PVP, quitosana e óxido de grafeno de reduzido (rGO) (PVP/Chi/rGO) como plataforma para imobilização da enzima lacase para detecção do hormônio sintético $17 \alpha$-etinilestradiol (EE2). ${ }^{182} \mathrm{O}$ biossensor proposto foi empregado para detecção amperométrica do EE2, mostrando um limite de detecção de $0,15 \mathrm{pmol} \mathrm{L}^{-1}$ e boa seletividade.

\section{Aplicações em energia}

NFs formadas por materiais condutores vêm sendo exploradas para o desenvolvimento de dispositivos para conversão e armazenamento de energia. ${ }^{20,149,162,213}$ Esses dispositivos são geralmente formados por polímeros condutores ou polímeros dopados com nanomateriais a base de carbono e óxidos semicondutores, visando boa condutividade elétrica. ${ }^{149}$ Ainda em relação a composição, NFs de carbono também são muito utilizadas e interessantes para aplicações em energia, devido à facilidade no controle da estrutura, morfologia e composição das mesmas e também por permitirem a incorporação de outros materiais, possibilitando a formação de nanoestruturas híbridas com propriedades eletrônicas, catalíticas e de adsorção únicas. ${ }^{213}$ Dentre as aplicações de NFs na área de energia, as mais frequentemente reportadas são: (i) formação de NGs que convertem energia mecânica em elétrica a partir do movimento/vibração do corpo humano; (ii) composição de células solares que convertem energia solar em elétrica; (iii) composição de baterias; (iv) formação de supercapacitores e (v) armazenamento/aprisionamento de hidrogênio. ${ }^{13,149,214,215}$ A principal aplicação dos NGs baseados em NFs é a de fornecer energia de forma sustentável para dispositivos eletrônicos vestíveis em aplicações biomédicas, como abordado anteriormente. 
Atualmente, tem-se uma alta demanda para o desenvolvimento de células solares eficientes, baterias recarregáveis, supercapacitores e dispositivos de armazenamento de hidrogênio, sendo que a eficiência desses dispositivos depende tanto do material utilizado quanto do método empregado em sua produção. ${ }^{149}$ Nesse sentido, as NFs podem atuar encurtando o caminho e aumentando a eficiência no transporte de carga, uma vez que configura via expressa de elétrons na direção axial. ${ }^{149}$

Em células solares, NFs são utilizadas na formação do componente sensibilizador (DSSCs - do inglês, Dye Solar Sensitive Cells), mais especificamente no desenvolvimento dos foto-ânodos, do contra-eletrodo ou das membranas eletrolíticas que formam os DSSCs. Para essa aplicação, materiais semicondutores como os polímeros condutores (devido seus efeitos fotovoltaicos) e os óxidos metálicos são os mais empregados. ${ }^{216} \mathrm{Cao}$ et al. desenvolveram

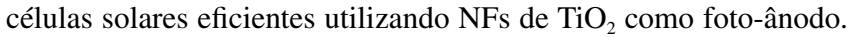
Para a produção dos foto-ânodos, NFs híbridas de $\mathrm{PVP}_{\mathrm{e}} \mathrm{TiO}_{2}$ foram coletadas em eletrodo de FTO e, posteriormente, calcinadas à $500^{\circ} \mathrm{C}$ por $2 \mathrm{~h}$. Após a calcinação, as NFs foram submetidas a tratamento hidrotérmico para formação de ramificações de $\mathrm{TiO}_{2}$. O dispositivo com estruturas ramificadas se mostrou mais eficiente na conversão de energia solar quando comparado ao filme precursor formado por NFs. ${ }^{100}$ Kaschuk et al. desenvolveram membranas eletrolíticas para melhoria da eficiência e durabilidade de células solares utilizando NFs formadas por acetato de celulose antes (CA) e após o processo de desacetilação (DCA). A Figura 6a mostra um esquema da configuração da célula solar desenvolvida e da deposição das NFs (membrana eletrolítica). A eficiência do dispositivo foi $14 \%$ maior em média quando comparada a células solares de referência. Testes de estabilidade e durabilidade mostraram que tanto CA quanto DCA mantêm sua performance por pelo menos $500 \mathrm{~h}^{217}$

No desenvolvimento de baterias de íons de Lítio (LIBs, do inglês Lithium-ion Batteries), NFs vêm sendo utilizadas como componentes do ânodo, ${ }^{218,220}$ do cátodo ${ }^{221}$ ou do separador, ${ }^{222,223}$ ou até mesmo dos três componentes para o desenvolvimento de baterias de alta performance. ${ }^{218}$ Jayaraman et al. desenvolveram bateria utilizando NFs de óxido de manganês lítio $\left(\mathrm{LiMn}_{2} \mathrm{O}_{4}\right)$ atuando como cátodo, NFs formadas pelo polímero poli(fluoreto de vinilidenoco-hexafluoropropileno) (PVdF-HFP) como separador e NFs de óxido de nióbio e titânio $\left(\mathrm{TiNb}_{2} \mathrm{O}_{7}\right)$ como ânodo, conforme mostra o esquema da Figura 6b. As NFs formadas por $\mathrm{LiMn}_{2} \mathrm{O}_{4}$ e $\mathrm{TiNb}_{2} \mathrm{O}_{7}$

(a)

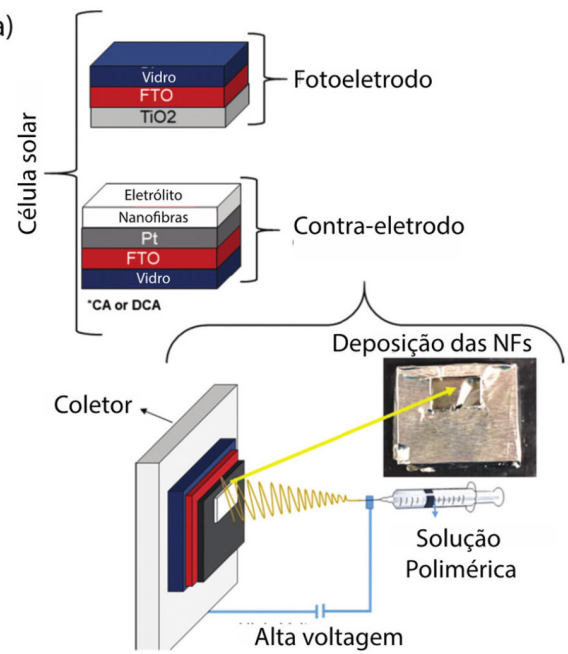

foram produzidas a partir de solução sol-gel onde o composto foi sintetizado utilizado o polímero PVP como suporte. ${ }^{218}$ Raulo et al. utilizaram NFs de PAN, recobertas com o polímero condutor poli $(3,4-$ etilenodioxitiofeno):poli(estirenosulfonado) (PEDOT:PSS), como aditivos flexíveis incorporados ao cátodo da bateria de lítio-enxofre, a fim de aprisionar polissufetos de lítio e suprimir sua dissolução em eletrólito líquido. A performance eletroquímica do cátodo contendo $\mathrm{o}$ aditivo mostrou-se significantemente melhor em estabilidade e capacidade comparado ao formado por enxofre apenas, devido ao efeito de adsorção das nanofibras. ${ }^{221}$

No desenvolvimento de supercapacitores, NFs de carbono vem sendo utilizadas como suporte para encapsular óxidos metálicos de transição, como o NiO, e polímeros condutores, como a PANI, para produção de dispositivo com elevada área de superfície, porosidade e boa condutividade. ${ }^{219} \mathrm{O}$ processo de desenvolvimento dos supercapacitores compreende, geralmente, a estruturação dos materiais híbridos através da eletrofiação e posterior carbonização, eliminando a fase orgânica. ${ }^{219,224-226} \mathrm{Li}$ et al. produziram NFs formadas pelo polímero PAN, nanopartículas de $\mathrm{NiO}$ e dicianodiamida (DCDA) para desenvolvimento de supercapacitores. A Figura 6c mostra imagens de MEV das NFs (i) antes e (ii) após o processo de carbonização à $800^{\circ} \mathrm{C}$. O detalhe na Figura 6 c(ii) mostra a formação de poros após a remoção da fase orgânica. ${ }^{219}$ São encontradas ainda na literatura alguns trabalhos que utilizam NFs no armazenamento de hidrogênio $\left(\mathrm{H}_{2}\right)$. Para tanto, as nanofibras são utilizadas na adsorção de estruturas híbridas metal-orgânicas (MOFs, do inglês Metallic Organic Frameworks), que são conhecidas pelas suas excelentes propriedades adsorventes de hidrogênio. Nas aplicações, a elevada porosidade das estruturas formadas por NFs de carbono permitem o armazenamento de grande quantidade de hidrogênio. ${ }^{227}$

A Tabela 5 apresenta alguns exemplos de aplicações de NFs em conversão e armazenamento de energia publicados na última década. A tabela relaciona o material empregado para a produção das NFs, a aplicação e a eficiência do dispositivo, além de apresentar as principais características dos mesmos.

\section{DO LABORATÓRIO PARA A INDÚSTRIA}

Como apresentado nas seções anteriores, a técnica de eletrofiação é altamente eficaz para a fabricação de nanofibras com várias morfologias, estruturas e tamanhos, a partir de uma ampla variedade (b)

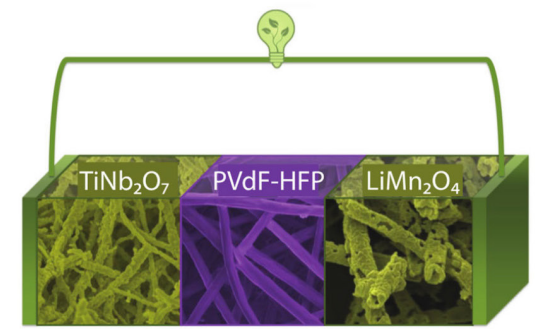

(c)

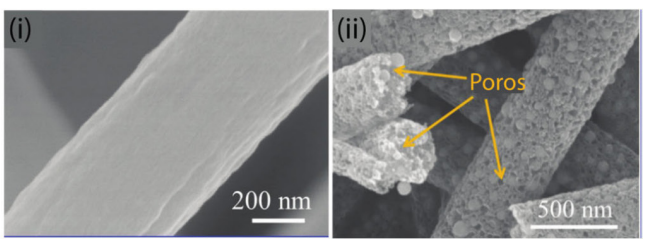

Figura 6. (a) Esquema de célula solar contendo NFs como membrana eletrolítica. O detalhe mostra a deposição das NFs de CA e DCA. Adaptada com permissão da referência 217. Copyright 2019 Springer Nature. (b) Representação de LIBs desenvolvida utilizando NFs como cátodo, separador e ânodo. Adaptada com permissão da referência 218. Copyright 2014 American Chemical Society. (c) Imagens MEV das NFs formadas por PAN/NiO/DCDA (i) antes e (ii) após o processo de carbonização à $800^{\circ} \mathrm{C}$. Adaptada com permissão da referência 219. Copyright 2018 John Wiley \& Sons 
Tabela 5. Exemplos de aplicações de NFs em conversão/armazenamento de energia

\begin{tabular}{|c|c|c|c|c|c|}
\hline Dispositivo & Aplicação & Material & Eficiência & Descrição & Ref. \\
\hline \multirow{5}{*}{ Células solares } & \multirow{2}{*}{$\begin{array}{l}\text { Formação do } \\
\text { foto-ânodo }\end{array}$} & & $6,26 \%$ & \multirow{2}{*}{$\begin{array}{c}\text { Efeito fotoelétrico do } \\
\mathrm{TiO}_{2} \text { na conversão de } \\
\text { energia }\end{array}$} & 100 \\
\hline & & $\mathrm{TiO}_{2 /} \mathrm{PVA}$ & $6,90 \%$ & & 228 \\
\hline & $\begin{array}{l}\text { Formação do } \\
\text { contra-eletrodo }\end{array}$ & $\mathrm{Co}_{3} \mathrm{~S}_{4} / \mathrm{ECs}^{\mathrm{a}}$ & $9,23 \%$ & $\begin{array}{l}\text { Atividade catalítica do } \\
\mathrm{Co}_{3} \mathrm{~S}_{4} \text { combinada com } \\
\text { eletrólito redox }\left(\mathrm{Co}^{3+/ 2+}\right)\end{array}$ & 229 \\
\hline & \multirow{2}{*}{$\begin{array}{c}\text { Formação das } \\
\text { membranas eletrolíticas }\end{array}$} & $\mathrm{CA}^{\mathrm{b}}$ e $\mathrm{DCA}^{\mathrm{c}}$ & $\begin{array}{c}4,0 \%(\mathrm{CA}) \\
3,7 \% \text { (DCA) }\end{array}$ & $\begin{array}{l}\text { Membranas melhoraram a } \\
\text { transferência de carga no } \\
\text { contra eletrodo }\end{array}$ & 217 \\
\hline & & $\mathrm{PVDF}^{\mathrm{d}}$ & $8,63 \%$ & $\begin{array}{l}\text { Membrana evita o } \\
\text { vazamento do eletrólito } \\
\text { e fornece canal para } \\
\text { transmissão de íons }\end{array}$ & 230 \\
\hline \multirow{5}{*}{$\begin{array}{l}\text { Baterias de íons de } \\
\text { Lítio (LIBs) }\end{array}$} & $\begin{array}{l}\text { Formação do } \\
\text { cátodo }\end{array}$ & PEDOT:PSS@PAN & $94 \%$ & $\begin{array}{c}\text { Aditivos flexíveis } \\
\text { adicionados ao cátodo }\end{array}$ & 221 \\
\hline & $\begin{array}{l}\text { Formação do } \\
\text { ânodo }\end{array}$ & $\mathrm{ZnO} / \mathrm{PAN}$ & $48,1 \%$ & $\begin{array}{l}\text { Formação de rede 3D } \\
\text { condutora }\end{array}$ & 220 \\
\hline & \multirow{2}{*}{$\begin{array}{l}\text { Formação do } \\
\text { separador }\end{array}$} & $\begin{array}{l}\mathrm{PI} / \mathrm{SiO}_{2} \\
\mathrm{PI} / \mathrm{Al}_{2} \mathrm{O}_{3}\end{array}$ & - & $\begin{array}{l}\text { Formação de separador } \\
\text { mais estável do que um } \\
\text { comercial }\end{array}$ & 223 \\
\hline & & PAN/PDC ${ }^{f}$ & - & $\begin{array}{l}\text { O separador utilizado } \\
\text { demonstra aumento na } \\
\text { capacidade de retenção }\end{array}$ & 222 \\
\hline & $\begin{array}{l}\text { Formação do cátodo, } \\
\text { ânodo e separador }\end{array}$ & $\begin{array}{c}\mathrm{TiNb}_{2} \mathrm{O}_{7} \\
\mathrm{PVdF}-\mathrm{HFP}^{\mathrm{g}} \\
\mathrm{LiMn}_{2} \mathrm{O}_{4} \\
\end{array}$ & $96 \%$ & $\begin{array}{l}\text { Bateria de Lítio com } \\
\text { todas as partes formadas } \\
\text { por NFs }\end{array}$ & 218 \\
\hline \multirow{4}{*}{ Supercapacitores } & \multirow{4}{*}{$\begin{array}{l}\text { Composição do } \\
\text { eletrodo e/ou } \\
\text { separador }\end{array}$} & PAN/PANI & $98-100 \%$ & $\begin{array}{l}\text { Flexibilidade e } \\
\text { excelente performance } \\
\text { eletroquímica }\end{array}$ & 224 \\
\hline & & $\mathrm{PAN} / \mathrm{NiO}$ & - & $\begin{array}{l}\text { Alta performance } \\
\text { eletroquímica }\end{array}$ & 219 \\
\hline & & PAN/PVP & - & $\begin{array}{l}\text { Alta capacitância e } \\
\text { excelente estabilidade }\end{array}$ & 225 \\
\hline & & PAN/CNT/PANI & $98 \%$ & Excelente estabilidade & 226 \\
\hline $\begin{array}{l}\text { Armazenamento de } \\
\text { hidrogênio }\end{array}$ & $\begin{array}{l}\text { Adsorção direta de } \\
\text { hidrogênio }\end{array}$ & PAN/MOF & $50 \%$ & Boa estabilidade térmica & 227 \\
\hline
\end{tabular}

${ }^{\mathrm{a}} \mathrm{ECs}$ - nanofibras de carbono; ${ }^{\mathrm{b}} \mathrm{CA}$ - acetato de celulose; ${ }^{\mathrm{DCA}}$ - acetato de celulose após processo de desacetilação; ${ }^{\mathrm{P} V V D F}$ - fluoreto de polivinilideno; ${ }^{\mathrm{e} P \mathrm{I}}$ - poliimida; ${ }^{\text {PDC }}$ - polímero derivado de cerâmica; ${ }^{\mathrm{g} P V D F}-\mathrm{HFP}$ - poli(fluoreto de vinilideno)-(hexafluoropropileno).

de materiais. Essa capacidade de projetar materiais com distintas propriedades abriu espaço para o surgimento de demandas de diferentes setores industriais para o desenvolvimento de NFs para aplicações específicas em diversas áreas. ${ }^{61,231,232}$ De acordo com os dados divulgados pela "Research and Markets", o mercado global de nanofibras pode chegar a 1 bilhão de dólares até o final de $2021 .^{20}$

$\mathrm{O}$ uso do processo de eletrofiação em escala comercial é resultado do trabalho de diversos pesquisadores e fabricantes. Nesse cenário, o trabalho desenvolvido em 1938, por Petryanov-Sokolov e colaboradores é considerado por muitos a primeira aplicação industrial de materiais eletrofiados. ${ }^{19}$ Eles aplicaram nanofibras obtidas a partir de uma matéria prima de nitrocelulose como filtros para a produção de máscaras de gás, que desde então são conhecidas na Rússia como "filtros de Petryanov". Em 1939, esse trabalho levou ao estabelecimento de uma fábrica em Tver, a Tver Carriage Works, para fabricação de filtros como máscaras de gás, sendo a primeira fábrica a produzir fibras eletrofiadas em escala industrial. ${ }^{20,36}$ Nos Estados Unidos, os primeiros produtos comerciais baseados em fibras eletrofiadas foram introduzidos no início da década de 80 pela Donaldson Company, Inc. Ainda na década de 80, a DuPont introduziu no mercado fibras de microdenier, dando início ao desenvolvimento de fibras inovadoras de alta performance. Em 1995, Reneker e colaboradores redescobriram a eletrofiação, evidenciando definitivamente sua natureza em nanoescala e o alto valor agregado dos nanomateriais eletrofiados..$^{231}$

Desde seu primórdio, tem se observado no cenário mundial um grande interesse por empresas de diferentes setores para comercialização de nanofibras, equipamentos de eletrofiação e suas soluções tecnológicas. ${ }^{19}$ Do ponto de vista da comercialização dos aparatos de eletrofiação, diferentes empresas possuem, em seus respectivos portfólios, equipamentos comerciais para produção de fibras em larga escala. ${ }^{105,233,234}$ Para garantir a transição do método de eletrofiação da escala de laboratório para a produção em escala industrial, aspectos como configuração do capilar, propriedades reológicas da solução, intensidade e distribuição do campo elétrico, vazão e geometria do coletor precisam ser avaliados de forma a garantir a produção de NFs com um alto rendimento. ${ }^{212}$ Além do processamento em grande volume, é preciso garantir a precisão e reprodutibilidade em todas as etapas de fabricação, além da segurança operacional. $^{24,231}$

Em escala laboratorial, a configuração mais típica do aparato de eletrofiação envolve o uso de uma única agulha e a taxa de produção 
típica associada a esse arranjo experimental é da ordem de 0,01 a $0,1 \mathrm{~g} \mathrm{~h}^{-1}$, o que limita bastante sua aplicabilidade na indústria. ${ }^{235}$ Uma das abordagens mais simples e fáceis para aumentar o volume de produção baseia-se na modificação do sistema de ejeção do polímero. ${ }^{231,236}$ Nesse cenário, uma das alternativas é o uso de sistemas com múltiplos capilares. No entanto, diferentes pesquisadores relatam desafios associados a esse tipo de configuração, incluindo: interação indesejável entre os jatos formados, causada pela interferência dos campos elétricos e as dificuldades no processo de limpeza de várias pontas o que eventualmente pode afetar a qualidade das nanofibras fabricadas. Além disso, o entupimento da ponta do capilar ocorre frequentemente devido ao seu pequeno diâmetro, impedindo o giro contínuo. O sistema multicanal também requer grande espaço para o equipamento, acarretando aumento de custo do processo de produção. ${ }^{231,235}$

Para superar esses desafios, a eletrofiação sem capilar, também conhecida como eletrofiação de superfície livre, vem sendo considerada um método eficaz para viabilizar a continuidade do processo de fabricação e, portanto, aumentar a produtividade. ${ }^{61,235}$ Ao contrário da eletrofiação convencional, na técnica de eletrofiação sem capilar, uma força elétrica é aplicada diretamente na superfície do líquido. Esse arranjo evita problemas de entupimento do capilar, facilitando o processo de formação de vários jatos, o que viabiliza uma maior produtividade, da ordem de $0,5 \mathrm{a} 600 \mathrm{~g} \mathrm{~h}^{-1}$. Até o momento, diferentes configurações de eletrofiação sem capilar foram reportadas com variação sistemática na geometria do mesmo. ${ }^{235,236} \mathrm{Um}$ exemplo desse sistema de eletrofiação é a Linha de Produção Nanospider desenvolvida pela Elmarco Inc. (https://www.elmarco.com), que usa um eletrodo de arame para ejetar vários jatos. Especificamente, a Nanospider NS 8S1600U é capaz de produzir até $20.000 .000 \mathrm{~m}^{2}$ por ano de uma manta de nanofibras com uma largura máxima de 1,6 m.

A adaptação do aparato experimental possibilitou a projeção e implementação de linhas de produção industrial por uma série de empresas para fabricação de NFs em grandes volumes. ${ }^{20}$ Dentre os produtos disponíveis no mercado, os voltados para filtração e purificação de gases e líquidos são os mais desenvolvidos. ${ }^{19,20,231}$ A empresa Revolution Fibers (https://www.revolutionfibres.com), por exemplo, desenvolveu um processo de eletrofiação capaz de produzir fibras a partir de uma ampla variedade de materiais para aplicações como membranas de filtração, cosméticos, área têxtil, eletrônicos, entre outras. Em 2010, a DuPont lançou o primeiro separador de bateria à base de NFs poliméricas, o Energain $^{\mathrm{TM}}$, capaz de aumentar a potência em 15 a $30 \%$, a vida útil da bateria em até $20 \%$ e melhorar a segurança da bateria, fornecendo estabilidade em altas temperaturas. ${ }^{19,231}$ Produtos voltados para aplicações na área biomédica também já foram lançados no mercado e outros continuam entrando em testes clínicos nos últimos anos. ${ }^{232}$ Nesse contexto, podem-se citar as empresas Xeltis (http://xeltis.com/), Nicast (http:// nicast.com/) e a Ortho ReBirth (https://orthorebirth.com). A primeira, uma empresa israelense, é responsável pela comercialização por exemplo de acessos vasculares para hemodiálise baseados em NFs, já a Ortho ReBirth tem sede no Japão e comercializa produtos voltados para medicina regenerativa.

\section{CONSIDERAÇÕES FINAIS E PERSPECTIVAS}

A técnica de eletrofiação evoluiu consideravelmente desde sua proposta inicial e, durante a última década, tem se mostrado como uma ferramenta extremamente versátil para obtenção de NFs a partir de vários materiais e com propriedades ajustáveis para um amplo espectro de aplicações. O grande potencial das NFs é devido à combinação de suas propriedades coletivas: (i) uma ampla gama de estruturas com diferentes morfologias pode ser obtida variando os parâmetros e configurações da técnica; (ii) as NFs obtidas possuem elevada porosidade e alta área superficial; (iii) diferentes materiais e técnicas podem ser empregadas na funcionalização das NFs para formar heteroestruturas hierárquicas. Além disso, nas últimas décadas, um grande progresso foi observado nas aplicações industriais de materiais eletrofiados devido aos esforços de várias empresas e grupos de pesquisa. No entanto, algumas limitações ainda precisam ser vencidas. Os pontos fracos existentes que devem ser superados incluem questões de segurança com o processo de eletrofiação em escala industrial devido ao uso de altas tensões e solventes inflamáveis, custo-benefício durante a produção e controle das propriedades das NFs (incluindo controle sobre diâmetro, morfologia, grau de alinhamento, etc.) e, consequentemente, da qualidade do produto comercializado, o que irá refletir no seu desempenho para aplicação de interesse. Espera-se que os desenvolvimentos de processos futuros evoluam por meio da cooperação efetiva entre os setores acadêmico e industrial, suprimindo as limitações da técnica de eletrofiação ainda existentes e reforçando suas potencialidades.

\section{AGRADECIMENTOS}

Os autores agradecem o apoio financeiro da Fundação de Amparo à Pesquisa do Estado de São Paulo (FAPESP 16/23793-4, 17/19470-8, 17/12174-4, 18/22214-6), do Conselho Nacional de Desenvolvimento Científico e Tecnológico (CNPq), do Ministério da Ciência, Tecnologia, Inovações e Comunicações (MCTI), do SisNano (CNPq/402.287/2013-4), da Coordenação de Aperfeiçoamento de Pessoal de Nível Superior (CAPES) e da Rede Agronano (EMBRAPA).

\section{REFERÊNCIAS}

1. Nasrollahzadeh, M.; Sajadi, S. M.; Sajjadi, M.; Issaabadi, Z. Interface Science and Technology; Elsevier Ltd., 2019; Vol. 28, pp. 113-143.

2. Bayda, S.; Adeel, M.; Tuccinardi, T.; Cordani, M.; Rizzolio, F.; Molecules 2020, 25, 112.

3. Saleh, T. A.; Environ. Technol. Innov. 2020, 20, 101067.

4. Pokropivny, V. V.; Skorokhod, V. V.; Phys. E Low-dimensional Syst. Nanostructures 2008, 40, 2521.

5. Dosch, H.; Appl. Surf. Sci. 2001, 182, 192.

6. Zarbin, A. J. G.; Quim. Nova 2007, 30, 1469.

7. Pokropivny, V. V.; Skorokhod, V. V.; Mater. Sci. Eng. C 2007, 27, 990.

8. Sandri, C.; Krieger, M. V.; Costa, W. C.; da Silva, A. R.; Bechtold, I. H.; Zimmermann, L. M.; Quim. Nova 2017, 40, 1215.

9. Burda, C.; Chen, X.; Narayanan, R.; El-Sayed, M. A.; Chem. Rev. 2005, 105, 1025.

10. Mageswari, A.; Srinivasan, R.; Subramanian, P.; Ramesh, N.; Gothandam, K. M. In Nanoscience in Food and Agriculture 3; Ranjan, S., Dasgupta, N., Lichtfouse, E., eds.; Springer: New York, 2016; Vol. 23, pp. 31-71.

11. Sudha, P. N.; Sangeetha, K.; Vijayalakshmi, K.; Barhoum, A. In Emerging Applications of Nanoparticles and Architecture Nanostructures; Barhoum, A., Makhlouf, A. S. H., eds.; Elsevier: Amsterdam, 2018; pp. 341-384.

12. Li, X.; Wang, J.; InfoMat 2020, 2, 3.

13. Hou, H.; Shao, G.; Yang, W.; Wong, W.-Y.; Prog. Mater. Sci. 2020, 113, 100671.

14. Lu, X.; Wang, C.; Wei, Y.; Small 2009, 5, 2349.

15. Pisignano, D.; Maruccio, G.; Mele, E.; Persano, L.; Di Benedetto, F.; Cingolani, R.; Appl. Phys. Lett. 2005, 87, 1.

16. Tu, D.; Pagliara, S.; Camposeo, A.; Potente, G.; Mele, E.; Cingolani, R.; Pisignano, D.; Adv. Funct. Mater. 2011, 21, 1140.

17. Guler, M. O.; Stupp, S. I.; J. Am. Chem. Soc. 2007, 129, 12082. 
18. Chiou, N.-R.; Lee, L. J.; Epstein, A. J.; Chem. Mater. 2007, 19, 3589.

19. Andleeb, A.; Yar, M. In Electrospun Materials and Their Allied Applications; Wiley, 2020; pp. 215-242.

20. Xue, J.; Wu, T.; Dai, Y.; Xia, Y.; Chem. Rev. 2019, 119, 5298.

21. Jian, S.; Zhu, J.; Jiang, S.; Chen, S.; Fang, H.; Song, Y.; Duan, G.; Zhang, Y.; Hou, H.; RSC Adv. 2018, 8, 4794.

22. Tebyetekerwa, M.; Ramakrishna, S.; Matter 2020, 2, 279.

23. Islam, M. S.; Ang, B. C.; Andriyana, A.; Afifi, A. M.; SN Appl. Sci. 2019, $1,1248$.

24. Thenmozhi, S.; Dharmaraj, N.; Kadirvelu, K.; Kim, H. Y.; Mater. Sci. Eng. B 2017, 217, 36.

25. Ramakrishna, S.; Fujihara, K.; Teo, W. E.; Yong, T.; Ma, Z.; Ramaseshan, R.; Mater. Today 2006, 9, 40.

26. Bhardwaj, N.; Kundu, S. C.; Biotechnol. Adv. 2010, $28,325$.

27. Wang, C.; Wang, J.; Zeng, L.; Qiao, Z.; Liu, X.; Liu, H.; Zhang, J.; Ding, J.; Molecules 2019, 24, 834.

28. Rossin, A.; de Oliveira, É.; de Moraes, F.; da S. Júnior, R.; Scheidt, D.; Caetano, W.; Hioka, N.; Dragunski, D.; Quim. Nova 2020, 43, 613.

29. Chen, S.; John, J. V.; McCarthy, A.; Xie, J.; J. Mater. Chem. B 2020, 8 , 3733.

30. Mercante, L. A.; Andre, R. S.; Mattoso, L. H. C.; Correa, D. S.; ACS Appl. Nano Mater. 2019, 2, 4026.

31. Mercante, L. A.; Scagion, V. P.; Migliorini, F. L.; Mattoso, L. H. C.; Correa, D. S.; TrAC - Trends Anal. Chem. 2017, 91, 91.

32. Terra, I.; Mercante, L.; Andre, R.; Correa, D.; Biosensors 2017, 7, 61.

33. Andre, R. S.; Mercante, L. A.; Facure, M. H. M.; Pavinatto, A.; Correa, D. S. In Electrospun Polymers and Composites; Elsevier, 2021; pp. 261-286.

34. Cooley, J. F.; US Pat. 692,631 1902, 693, 1.

35. Doshi, J.; Reneker, D. H.; J. Electrostat. 1995, 35, 151.

36. Ghosal, K.; Agatemor, C.; Tucker, N.; Kny, E.; Thomas, S. In Electrospinning: From Basic Research to Commercialization; The Royal Society of Chemistry, 2018; pp. 1-23.

37. Zhang, C. L.; Yu, S. H.; Chem. Soc. Rev. 2014, 43, 4423.

38. Xue, J.; Xie, J.; Liu, W.; Xia, Y.; Acc. Chem. Res. 2017, 50, 1976.

39. Costa, R. G. F.; Oliveira, J. E. de; Paula, G. F. de; Picciani, P. H. de S.; Medeiros, E. S. de; Ribeiro, C.; Mattoso, L. H. C.; Polímeros 2012, 22 , 170.

40. Patel, K. D.; Kim, H. W.; Knowles, J. C.; Poma, A.; Adv. Funct. Mater. 2020, 2001955.

41. Reneker, D. H.; Chun, I.; Nanotechnology 1996, 7, 216.

42. Reneker, D. H.; Yarin, A. L.; Polymer (Guildf). 2008, 49, 2387.

43. Sun, B.; Long, Y. Z.; Zhang, H. D.; Li, M. M.; Duvail, J. L.; Jiang, X. Y.; Yin, H. L.; Prog. Polym. Sci. 2014, 39, 862.

44. Maria Leena, M.; Vimala Bharathi, S. K.; Moses, J. A.; Anandharamakrishnan, C. In Nanoengineering in the Beverage Industry; Grumezescu, A., Holban, A. M., eds.; Elsevier: Amsterdam, 2020; pp. 333-368

45. Collins, G.; Federici, J.; Imura, Y.; Catalani, L. H.; J. Appl. Phys. 2012, 111.

46. Soltani, S.; Khanian, N.; Choong, T. S. Y.; Rashid, U.; New J. Chem. 2020, 44, 9581.

47. Liu, G.; Gu, Z.; Hong, Y.; Cheng, L.; Li, C.; J. Control. Release 2017, $252,95$.

48. Medeiros, E. S.; Mattoso, L. H. C.; Offeman, R. D.; Wood, D. F.; Orts, W. J.; Can. J. Chem. 2008, 86, 590.

49. Haider, A.; Haider, S.; Kang, I.-K.; Arab. J. Chem. 2018, 11, 1165.

50. Mishra, R. K.; Mishra, P.; Verma, K.; Mondal, A.; Chaudhary, R. G.; Abolhasani, M. M.; Loganathan, S.; Environ. Chem. Lett. 2019, 17, 767.

51. Ahmed, F. E.; Lalia, B. S.; Hashaikeh, R.; Desalination 2015, 356, 15.

52. Ramakrishna, S.; Fujihara, K.; Teo, W.-E.; Lim, T.-C.; Ma, Z. An Introduction to Electrospinning and Nanofibers; World Scientific: Singapore, 2005.
53. Tijing, L. D.; Yao, M.; Ren, J.; Park, C.-H.; Kim, C. S.; Shon, H. K. In Water and Wastewater Treatment Technologies, Energy, Environment, and Sustainability; Bui, X.-T., Chiemchaisri, C., Fujioka, T., Varjani, S., eds.; Springer: New York, 2019; pp. 431-468.

54. Patil, J. V.; Mali, S. S.; Kamble, A. S.; Hong, C. K.; Kim, J. H.; Patil, P. S.; Appl. Surf. Sci. 2017, 423, 641.

55. Shao, H.; Fang, J.; Wang, H.; Lin, T.; RSC Adv. 2015, 5, 14345.

56. Herrero-Herrero, M.; Gómez-Tejedor, J. A.; Vallés-Lluch, A.; Eur Polym. J. 2018, 99, 445.

57. Teo, W. E.; Ramakrishna, S.; Nanotechnology 2006, 17, R89.

58. Cui, J.; Li, F.; Wang, Y.; Zhang, Q.; Ma, W.; Huang, C.; Sep. Purif. Technol. 2020, 250, 117116.

59. Jung, J. W.; Lee, C. L.; Yu, S.; Kim, I. D.; J. Mater. Chem. A 2016, 4, 703.

60. Polini, A.; Yang, F. In Nanofiber Composites for Biomedical Applications; Ramalingam, M., Ramakrishna, S., eds.; Elsevier: Amsterdam, 2017; pp. 97-115.

61. Yu, M.; Dong, R.-H.; Yan, X.; Yu, G.-F.; You, M.-H.; Ning, X.; Long, Y.-Z.; Macromol. Mater. Eng. 2017, 302, 1700002.

62. Leidy, R.; Maria Ximena, Q.-C.; Trends Food Sci. Technol. 2019, 85, 92.

63. Machado, B.; Roberto, S.; Bonafé, E.; Camargo, S.; Camargo, C.; Popat, K.; Kipper, M.; Martins, A.; J. Braz. Chem. Soc. 2019, 30, 1741.

64. Migliorini, F. L.; Sanfelice, R. C.; Mercante, L. A.; Andre, R. S.; Mattoso, L. H. C.; Correa, D. S.; Appl. Surf. Sci. 2018, 443, 18.

65. Huang, C.; Thomas, N. L.; Polym. Rev. 2020, 60, 595.

66. Huang, Z.-M.; Zhang, Y.-Z.; Kotaki, M.; Ramakrishna, S.; Compos. Sci. Technol. 2003, 63, 2223.

67. Costa, R. G. F.; Oliveira, J. E. de; Paula, G. F. de; Picciani, P. H. de S.; Medeiros, E. S. de; Ribeiro, C.; Mattoso, L. H. C.; Polímeros 2012, 22, 178.

68. Sridhar, R.; Lakshminarayanan, R.; Madhaiyan, K.; Amutha Barathi, V.; Lim, K. H. C.; Ramakrishna, S.; Chem. Soc. Rev. 2015, 44, 790.

69. Wang, X.-X.; Yu, G.-F.; Zhang, J.; Yu, M.; Ramakrishna, S.; Long, Y.-Z.; Prog. Mater. Sci. 2021, 115, 100704.

70. Celebioglu, A.; Uyar, T.; J. Colloid Interface Sci. 2013, 404, 1.

71. Celebioglu, A.; Uyar, T.; Nanoscale 2012, 4, 621.

72. Ifuku, S.; Saimoto, H.; Nanoscale 2012, 4, 3308.

73. Juncos Bombin, A. D.; Dunne, N. J.; McCarthy, H. O.; Mater. Sci. Eng. C 2020, 114, 110994.

74. Hoque, M. E.; Nuge, T.; Yeow, T. K.; Nordin, N. In Nanostructured Polymer Composites for Biomedical Applications; Swain, S. K., Jawaid, M., eds.; Elsevier: Amsterdam, 2019; pp. 87-104.

75. Liao, Y.; Loh, C.-H.; Tian, M.; Wang, R.; Fane, A. G.; Prog. Polym. Sci. 2018, 77, 69.

76. Kausar, A.; J. Plast. Film Sheeting 2020, 1

77. Schneider, R.; Mercante, L. A.; Andre, R. S.; Brandão, H. de M.; Mattoso, L. H. C.; Correa, D. S.; React. Funct. Polym. 2018, 132, 26.

78. Zhang, D.; Jin, X.-Z.; Huang, T.; Zhang, N.; Qi, X.; Yang, J.; Zhou, Z.; Wang, Y.; ACS Appl. Mater. Interfaces 2019, 11, 5073.

79. Tomczak, N.; Van Hulst, N. F.; Vancso, G. J.; Macromolecules 2005, 38, 7863.

80. Hou, Z.; Yang, P.; Lian, H.; Wang, L.; Zhang, C.; Li, C.; Chai, R.; Cheng, Z.; Lin, J.; Chem. - Eur. J. 2009, 15, 6973.

81. Chen, H.; Di, J.; Wang, N.; Dong, H.; Wu, J.; Zhao, Y.; Yu, J.; Jiang, L.; Small 2011, 7, 1779.

82. Liu, H.; Han, C.; Shao, C.; Yang, S.; Li, X.; Li, B.; Li, X.; Ma, J.; Liu, Y.; ACS Appl. Nano Mater. 2019, 2, 4879.

83. Chi, Q.; Wang, X.; Zhang, C.; Chen, Q.; Chen, M.; Zhang, T.; Gao, L.; Zhang, Y.; Cui, Y.; Wang, X.; Lei, Q.; ACS Sustain. Chem. Eng. 2018, 6, 8641.

84. Wang, G.; Ma, Q.; Tian, J.; Fan, L.; Li, D.; Dong, X.; Yu, W.; Wang, J.; Liu, G.; $R S C A d v$. 2019, 9, 206.

85. Inagaki, M.; Yang, Y.; Kang, F.; Adv. Mater. 2012, 24, 2547. 
86. Zhang, L.; Aboagye, A.; Kelkar, A.; Lai, C.; Fong, H.; J. Mater. Sci. 2014, 49, 463.

87. Li, D.; Xia, Y.; Nano Lett. 2003, 3, 555.

88. Esfahani, H.; Jose, R.; Ramakrishna, S.; Materials (Basel) 2017, 10, 1238.

89. Simonsen, S. B.; Shao, J.; Zhang, W.; Nanotechnology 2017, 28, 265402.

90. Senthamizhan, A.; Balusamy, B.; Aytac, Z.; Uyar, T.; CrystEngComm 2016, 18,6341 .

91. Albetran, H.; O’Connor, B. H.; Low, I. M.; Mater. Des. 2016, 92, 480.

92. Katoch, A.; Choi, S.-W.; Kim, S. S.; Met. Mater. Int. 2015, 21, 213.

93. Sigmund, W.; Yuh, J.; Park, H.; Maneeratana, V.; Pyrgiotakis, G.; Daga, A.; Taylor, J.; Nino, J. C.; J. Am. Ceram. Soc. 2006, 89, 395.

94. Simon, I. A.; Medeiros, N. G.; Garcia, K. C.; Soares, R. M. D.; Rosa, A. T.; Silva, J. A.; J. Braz. Chem. Soc. 2015, 26, 1710.

95. Rani, S. D.; Ramachandran, R.; Sheet, S.; Aziz, M. A.; Lee, Y. S.; AlSehemi, A. G.; Pannipara, M.; Xia, Y.; Tsai, S. Y.; Ng, F. L.; Phang, S. M.; Kumar, G. G.; Sens. Actuators, B 2020, 312, 127886.

96. Xu, C.; Shi, S.; Wang, X.; Zhou, H.; Wang, L.; Zhu, L.; Zhang, G.; Xu, D.; J. Hazard. Mater. 2020, 381, 120974.

97. Shan, H.; Wang, X.; Shi, F.; Yan, J.; Yu, J.; Ding, B.; ACS Appl. Mater. Interfaces 2017, 9, 18966.

98. Li, W.; Ma, S.; Li, Y.; Yang, G.; Mao, Y.; Luo, J.; Gengzang, D.; Xu, X.; Yan, S.; Sens. Actuators, B 2015, 211, 392.

99. Cao, J.; Wang, S.; Zhang, H.; Zhang, T.; J. Alloys Compd. 2019, 799, 513.

100. Cao, Y.; Dong, Y.-J.; Feng, H.-L.; Chen, H.-Y.; Kuang, D.-B.; Electrochim. Acta 2016, 189, 259.

101. Choi, J.; Chan, S.; Joo, H.; Yang, H.; Ko, F. K.; Water Res. 2016, 101, 362.

102. Wu, N.; Wang, B.; Wang, Y.; J. Am. Ceram. Soc. 2018, 101, 4763.

103. Li, X.; Wang, J.; Li, M.; Jin, Y.; Gu, Z.; Liu, C.; Ogino, K.; Chinese Chem. Lett. 2018, 29, 527.

104. Yoon, J.; Yang, H.-S.; Lee, B.-S.; Yu, W.-R.; Adv. Mater. 2018, 30, 1704765 .

105. Han, D.; Steckl, A. J.; ChemPlusChem 2019, 84, 1453.

106. Tang, Y.; Chen, L.; Zhao, K.; Wu, Z.; Wang, Y.; Tan, Q.; Compos. Sci. Technol. 2016, 125, 100.

107. Lv, R.; Li, S.; Jin, T.; Na, B.; Zhou, H.; Liu, H.; Compos. Sci. Technol. 2018, 162,58

108. Huang, B.; Zhang, Z.; Zhao, C.; Cairang, L.; Bai, J.; Zhang, Y.; Mu, X.; Du, J.; Wang, H.; Pan, X.; Zhou, J.; Xie, E.; Sens. Actuators, B 2018, $255,2248$.

109. Awada, H.; Al Samad, A.; Laurencin, D.; Gilbert, R.; Dumail, X.; El Jundi, A.; Bethry, A.; Pomrenke, R.; Johnson, C.; Lemaire, L.; Franconi, F.; Félix, G.; Larionova, J.; Guari, Y.; Nottelet, B.; ACS Appl. Mater. Interfaces 2019, 11, 9519.

110. Han, N. K.; Choi, Y. C.; Park, D. U.; Ryu, J. H.; Jeong, Y. G.; Compos. Sci. Technol. 2020, 196, 108212.

111. Chen, G.; Xu, Y.; Yu, D.-G.; Zhang, D.-F.; Chatterton, N. P.; White, K. N.; Chem. Commun. 2015, 51, 4623.

112. dos Santos, D. M.; Correa, D. S.; Medeiros, E. S.; Oliveira, J. E.; Mattoso, L. H. C.; ACS Appl. Mater. Interfaces 2020, 12, 45673.

113. Liu, Z.; Ramakrishna, S.; Liu, X.; APL Bioeng. 2020, 4, 030901.

114. Gao, J.; Wang, L.; Guo, Z.; Li, B.; Wang, H.; Luo, J.; Huang, X.; Xue, H.; Chem. Eng. J. 2020, 381, 122778.

115. Doostmohammadi, M.; Forootanfar, H.; Ramakrishna, S.; Mater. Sci. Eng. C 2020, 109, 110521.

116. Çay, A.; Akçakoca Kumbasar, E. P.; Keskin, Z.; Akduman, Ç.; 冈endemir Ürkmez, A.; J. Mater. Sci. 2017, 52, 12098.

117. Trinca, R. B.; Westin, C. B.; da Silva, J. A. F.; Moraes, Â. M.; Eur. Polym. J. 2017, 88, 161.

118. Yin, A.; Zhang, K.; McClure, M. J.; Huang, C.; Wu, J.; Fang, J.; Mo, X.;
Bowlin, G. L.; Al-Deyab, S. S.; El-Newehy, M.; J. Biomed. Mater. Res. Part A 2013, 101A, 1292.

119. Chakraborty, P. K.; Adhikari, J.; Saha, P.; Int. J. Biol. Macromol. 2019, 122,644

120. Mehrasa, M.; Asadollahi, M. A.; Ghaedi, K.; Salehi, H.; Arpanaei, A.; Int. J. Biol. Macromol. 2015, 79, 687.

121. Yeo, M.; Kim, G.; Chem. Eng. J. 2015, 275, 27.

122. Ren, X.; Han, Y.; Wang, J.; Jiang, Y.; Yi, Z.; Xu, H.; Ke, Q.; Acta Biomater. 2018, 70, 140 .

123. Hu, W.-W.; Wu, Y.-C.; Hu, Z.-C.; Carbohydr. Polym. 2018, 183, 29.

124. Gong, T.; Liu, T.; Zhang, L.; Ye, W.; Guo, X.; Wang, L.; Quan, L.; Pan, C.; ACS Biomater. Sci. Eng. 2018, 4, 240.

125. Yu, D. G.; Li, X. Y.; Wang, X.; Yang, J. H.; Bligh, S. W. A.; Williams, G. R.; ACS Appl. Mater. Interfaces 2015, 7, 18891.

126. Yang, Y.; Li, W.; Yu, D.-G.; Wang, G.; Williams, G. R.; Zhang, Z.; Carbohydr. Polym. 2019, 203, 228.

127. Choi, S.; Moon, S. H.; Kim, T. K.; Kim, H. S.; Polym. Int. 2019, 68, 1921.

128. Wang, Q.; Jian, M.; Wang, C.; Zhang, Y.; Adv. Funct. Mater. 2017, 27, 1605657.

129. Ren, H.; Zheng, L.; Wang, G.; Gao, X.; Tan, Z.; Shan, J.; Cui, L.; Li, K.; Jian, M.; Zhu, L.; Zhang, Y.; Peng, H.; Wei, D.; Liu, Z.; ACS Nano 2019, 13, 5541 .

130. Ghosh, S. K.; Adhikary, P.; Jana, S.; Biswas, A.; Sencadas, V.; Gupta, S. D.; Tudu, B.; Mandal, D.; Nano Energy 2017, 36, 166.

131. Wang, G.; Liu, T.; Sun, X.-C.; Li, P.; Xu, Y.-S.; Hua, J.-G.; Yu, Y.-H.; Li, S.-X.; Dai, Y.-Z.; Song, X.-Y.; Lv, C.; Xia, H.; Sens. Actuators, A 2018 , $280,319$.

132. Lin, S.; Cheng, Y.; Mo, X.; Chen, S.; Xu, Z.; Zhou, B.; Zhou, H.; Hu, B.; Zhou, J.; Nanoscale Res. Lett. 2019, 14, 251.

133. You, X.; He, J.; Nan, N.; Sun, X.; Qi, K.; Zhou, Y.; Shao, W.; Liu, F.; Cui, S.; J. Mater. Chem. C 2018, 6, 12981.

134. Wang, Y.; Li, W.; Zhou, Y.; Jiang, L.; Ma, J.; Chen, S.; Jerrams, S.; Zhou, F.; J. Mater. Sci. 2020, 55, 12592.

135. Zhou, Y.; He, J.; Wang, H.; Qi, K.; Nan, N.; You, X.; Shao, W.; Wang, L.; Ding, B.; Cui, S.; Sci. Rep. 2017, 7, 12949.

136. Kim, K. O.; Kim, G. J.; Kim, J. H.; RSC Adv. 2019, 9, 22790.

137. Braghirolli, D. I.; Steffens, D.; Pranke, P.; Drug Discov. Today 2014, 19, 743.

138. Ogueri, K. S.; Laurencin, C. T.; ACS Nano 2020, 14, 9347.

139. Yao, Q.; Cosme, J. G. L.; Xu, T.; Miszuk, J. M.; Picciani, P. H. S.; Fong, H.; Sun, H.; Biomaterials 2017, 115, 115.

140. Ner, Y.; Asemota, C.; Olson, J. R.; Sotzing, G. A.; ACS Appl. Mater. Interfaces 2009, 1, 2093.

141. Hong, J.; Yeo, M.; Yang, G. H.; Kim, G.; Int. J. Mol. Sci. 2019, 20, 6208.

142. Ehler, E.; Jayasinghe, S. N.; Analyst 2014, 139, 4449.

143. Hu, X.; Liu, S.; Zhou, G.; Huang, Y.; Xie, Z.; Jing, X.; J. Control. Release 2014, 185, 12 .

144. Locilento, D. A.; Mercante, L. A.; Andre, R. S.; Mattoso, L. H. C.; Luna, G. L. F.; Brassolatti, P.; Anibal, F. D. F.; Correa, D. S.; J. Nanomater. 2019, 2019, 1.

145. Salles, G. N.; Calió, M. L.; Afewerki, S.; Pacheco-Soares, C.; Porcionatto, M.; Hölscher, C.; Lobo, A. O.; ACS Appl. Mater. Interfaces 2018, 10, 36693.

146. Parham, S.; Kharazi, A. Z.; Bakhsheshi-Rad, H. R.; Ghayour, H.; Ismail, A. F.; Nur, H.; Berto, F.; Materials (Basel) 2020, 13, 2153.

147. Shi, J.; Liu, S.; Zhang, L.; Yang, B.; Shu, L.; Yang, Y.; Ren, M.; Wang, Y.; Chen, J.; Chen, W.; Chai, Y.; Tao, X.; Adv. Mater. 2020, 32, 1.

148. Mokhtari, F.; Cheng, Z.; Raad, R.; Xi, J.; Foroughi, J.; J. Mater. Chem. A 2020, 8, 9496.

149. Chinnappan, A.; Baskar, C.; Baskar, S.; Ratheesh, G.; Ramakrishna, S.; J. Mater. Chem. C 2017, 5, 12657.

150. Wu, Z.; Cheng, T.; Wang, Z. L.; Sensors 2020, 20, 2925. 
151. Li, C.; Cao, R.; Zhang, X.; Appl. Sci. 2018, 8, 2485.

152. Zhu, M.; Chng, S. S.; Cai, W.; Liu, C.; Du, Z.; RSC Adv. 2020, 10, 21887.

153. Zang, Y.; Zhang, F.; Huang, D.; Gao, X.; Di, C.; Zhu, D.; Nat. Commun. $\mathbf{2 0 1 5}, 6,6269$.

154. Wang, X.; Yang, B.; Liu, J.; Zhu, Y.; Yang, C.; He, Q.; Sci. Rep. 2016, 6, 36409.

155. Kenry; Yeo, J. C.; Lim, C. T.; Microsystems Nanoeng. 2016, 2, 16043.

156. Horne, J.; McLoughlin, L.; Bridgers, B.; Wujcik, E. K.; Sensors and Actuators Reports 2020, 2, 100005.

157. des Ligneris, E.; Dumée, L.; Kong, L.; Appl. Sci. 2018, 8, 166.

158. Chen, H.; Huang, M.; Liu, Y.; Meng, L.; Ma, M.; Sci. Total Environ. 2020, 739, 139944.

159. Zhu, M.; Han, J.; Wang, F.; Shao, W.; Xiong, R.; Zhang, Q.; Pan, H. Yang, Y.; Samal, S. K.; Zhang, F.; Huang, C.; Macromol. Mater. Eng. 2017, 302, 1600353.

160. Correa, D. S.; Mercante, L. A.; Schneider, R.; Facure, M. H. M.; Locilento, D. A. In Handbook of Ecomaterials; Torres-Martinez, L. M., Kharissova, O. V., Kharisov, B. I., eds.; Springer International Publishing: Cham, 2018; pp. 1-29.

161. Kumar, P. S.; Sundaramurthy, J.; Sundarrajan, S.; Babu, V. J.; Singh, G.; Allakhverdiev, S. I.; Ramakrishna, S.; Energy Environ. Sci. 2014, 7, 3192.

162. Thavasi, V.; Singh, G.; Ramakrishna, S.; Energy Environ. Sci. 2008, 1, 205.

163. Xiong, C.; Quan, Z.; Zhang, H.; Wang, L.; Qin, X.; Wang, R.; Yu, J.; Appl. Surf. Sci. 2020, 532, 147400.

164. Liu, C.; Hsu, P.-C.; Lee, H.-W.; Ye, M.; Zheng, G.; Liu, N.; Li, W.; Cui, Y.; Nat. Commun. 2015, 6, 6205.

165. Mercante, L. A.; Andre, R. S.; Schneider, R.; Mattoso, L. H. C.; Correa, D. S.; New J. Chem. 2020, 44, 13030.

166. Li, X.; Wang, N.; Fan, G.; Yu, J.; Gao, J.; Sun, G.; Ding, B.; J. Colloid Interface Sci. 2015, 439, 12.

167. Liu, K.; Liu, C.; Hsu, P.-C.; Xu, J.; Kong, B.; Wu, T.; Zhang, R.; Zhou, G.; Huang, W.; Sun, J.; Cui, Y.; ACS Cent. Sci. 2018, 4, 894.

168. Yu, Y.; Ma, Q.; Zhang, J.; Liu, G.; Appl. Surf. Sci. 2020, 512, 145697.

169. Yin, X.; Zhang, Z.; Ma, H.; Venkateswaran, S.; Hsiao, B. S.; Sep. Purif. Technol. 2020, 242.

170. Zhou, C.; Zhang, Y.; Liu, H.; J. Braz. Chem. Soc. 2018, 29, 457.

171. Shariful, M. I.; Sepehr, T.; Mehrali, M.; Ang, B. C.; Amalina, M. A.; J. Appl. Polym. Sci. 2018, 135, 45851.

172. Xu, Z.; Wei, C.; Jin, J.; Xu, W.; Wu, Q.; Gu, J.; Ou, M.; Xu, X.; J. Braz. Chem. Soc. 2017, 29, 560.

173. Du, F.; Sun, L.; Huang, Z.; Chen, Z.; Xu, Z.; Ruan, G.; Zhao, C.; Chemosphere 2020, 239, 124764.

174. Riaz, S.; Park, S.-J.; J. Ind. Eng. Chem. 2020, 84, 23.

175. Taha, A. A.; Hriez, A. A.; Wang, H.; Wu, Y.; Li, F.; RSC Adv. 2014, 4, 5901.

176. Kanjwal, M. A.; Chronakis, I. S.; Barakat, N. A. M.; Ceram. Int. 2015, 41,12229

177. Zhong, Y.; Qiu, X.; Chen, D.; Li, N.; Xu, Q.; Li, H.; He, J.; Lu, J.; ACS Appl. Mater. Interfaces 2016, 8, 28671.

178. Han, N.; Wang, W.; Lv, X.; Zhang, W.; Yang, C.; Wang, M.; Kou, X.; Li, W.; Dai, Y.; Zhang, X.; ACS Appl. Mater. Interfaces 2019, 11, 46920.

179. Yang, T.; Zhan, L.; Huang, C. Z.; TrAC Trends Anal. Chem. 2020, 124, 115813.

180. Wang, Z.; Wu, S.; Wang, J.; Yu, A.; Wei, G.; Nanomaterials 2019, 9 , 1045.

181. Venkatesan, M.; Veeramuthu, L.; Liang, F. C.; Chen, W. C.; Cho, C. J.; Chen, C. W.; Chen, J. Y.; Yan, Y.; Chang, S. H.; Kuo, C. C.; Chem. Eng. J. 2020, 397, 125431.

182. Pavinatto, A.; Mercante, L. A.; H. M. Facure, M.; Pena, R. B.; Sanfelice, R. C.; H. C. Mattoso, L.; Correa, D. S.; Appl. Surf. Sci. 2018, 458, 431.
183. Furquim, F. C.; Santos, E. N.; Mercante, L. A.; Amaral, M. M.; Pavinatto, A.; Rodrigues, B. V. M.; Mater. Lett. 2020, 274, 128014.

184. Li, Y.; Wang, L.; Yin, X.; Ding, B.; Sun, G.; Ke, T.; Chen, J.; Yu, J.; J. Mater. Chem. A 2014, 2, 18304.

185. Oliveira, V. H. B.; Rechotnek, F.; da Silva, E. P.; Marques, V. de S.; Rubira, A. F.; Silva, R.; Lourenço, S. A.; Muniz, E. C.; J. Mol. Liq. 2020, 309, 113041.

186. Liu, T.; Guo, Y.; Zhang, Z.; Miao, Z.; Zhang, X.; Su, Z.; Sens. Actuators, B 2019, 286, 370 .

187. Mane, P. P.; Ambekar, R. S.; Kandasubramanian, B.; Int. J. Pharm. 2020, 583.

188. Patil, P. T.; Anwane, R. S.; Kondawar, S. B.; Procedia Mater. Sci. 2015, $10,195$.

189. Andre, R. S.; Mercante, L. A.; Facure, M. H. M.; Mattoso, L. H. C.; Correa, D. S.; Appl. Surf. Sci. 2019, 473, 133.

190. Andre, R.; Kwak, D.; Dong, Q.; Zhong, W.; Correa, D.; Mattoso, L.; Lei, Y.; Sensors 2018, 18, 1058.

191. Hou, S.; Pang, R.; Chang, S.; Ye, L.; Xu, J.; Wang, X.; Zhang, Y.; Shang, Y.; Cao, A.; ACS Appl. Mater. Interfaces 2020, 12, acsami.0c05953.

192. Li, W.-T.; Zhang, X.-D.; Guo, X.; Sens. Actuators B 2017, 244, 509.

193. Kuntzler, S. G.; Costa, J. A. V.; Brizio, A. P. D. R.; Morais, M. G. de; Food Chem. 2020, 328, 126768.

194. Hwang, S. H.; Kim, Y. K.; Jeong, S. M.; Choi, C.; Son, K. Y.; Lee, S. K.; Lim, S. K.; Text. Res. J. 2020, 90, 2198.

195. Abedalwafa, M. A.; Tang, Z.; Qiao, Y.; Mei, Q.; Yang, G.; Li, Y.; Wang, L.; Microchim. Acta 2020, 187, 360.

196. Terra, I. A. A.; Sanfelice, R. C.; Scagion, V. P.; Tomazio, N. B.; Mendonça, C. R.; Nunes, L. A. O.; Correa, D. S.; J. Appl. Polym. Sci. 2019, 136, 47775 .

197. Terra, I. A. A.; Sanfelice, R. C.; Valente, G. T.; Correa, D. S.; J. Appl. Polym. Sci. 2018, 135, 46128.

198. Lv, Y.; Zhang, Y.; Du, Y.; Xu, J.; Wang, J.; Sensors 2013, 13, 15758.

199. Zhou, C.; Liu, H.; J. Braz. Chem. Soc. 2017, 28, 1947.

200. Cabral, T. S.; Sgobbi, L. F.; Delezuk, J.; Pessoa, R. S.; Lobo, A. O.; Rodrigues, B. V. M.; Mater. Today Proc. 2019, 14, 694

201. Migliorini, F. L.; Sanfelice, R. C.; Mercante, L. A.; Facure, M. H. M.; Correa, D. S.; Mater. Res. Express 2020, 7, 015601.

202. Zhao, D.; Lu, Y.; Ding, Y.; Fu, R.; Sens. Actuators, B 2017, 241, 601.

203. Andre, R. S.; Pavinatto, A.; Mercante, L. A.; Paris, E. C.; Mattoso, L. H. C.; Correa, D. S.; RSC Adv. 2015, 5, 73875

204. Dey, A.; Mater. Sci. Eng. B 2018, 229, 206.

205. Mirzaei, A.; Kumar, V.; Bonyani, M.; Majhi, S. M.; Bang, J. H.; Kim, J.Y.; Kim, H. W.; Kim, S. S.; Kim, K.-H.; Asian J. Atmos. Environ. 2020, 14,85 .

206. Homocianu, M.; Pascariu, P.; Polym. Rev. 2020, 60, 493.

207. Chen, B.-Y.; Kuo, C.-C.; Huang, Y.-S.; Lu, S.-T.; Liang, F.-C.; Jiang, D.-H.; ACS Appl. Mater. Interfaces 2015, 7, 2797.

208. Balusamy, B.; Senthamizhan, A.; Uyar, T.; Materials (Basel) 2020, 13, 2421.

209. Cho, C.; Lu, S.; Kuo, C.; Liang, F.; Chen, B.; Chu, C.; React. Funct. Polym. 2016, 108, 137.

210. Shaibani, P. M.; Jiang, K.; Haghighat, G.; Hassanpourfard, M.; Etayash, H.; Naicker, S.; Thundat, T.; Sens. Actuators, B 2016, 226, 176.

211. Supraja, P.; Tripathy, S.; Krishna Vanjari, S. R.; Singh, V.; Singh, S. G.; Biosens. Bioelectron. 2019, 141, 111441.

212. Al-Dhahebi, A. M.; Gopinath, S. C. B.; Saheed, M. S. M.; Nano Converg. 2020, 7, 27.

213. Peng, S.; Li, L.; Kong Yoong Lee, J.; Tian, L.; Srinivasan, M.; Adams, S.; Ramakrishna, S.; Nano Energy 2016, 22, 361.

214. Da Silva, E. P.; Rubira, A. F.; Ferreira, O. P.; Silva, R.; Muniz, E. C.; J. Colloid Interface Sci. 2019, 555, 373.

215. Liang, J.; Zhao, H.; Yue, L.; Fan, G.; Li, T.; Lu, S.; Chen, G.; Gao, S.; Asiri, A. M.; Sun, X.; J. Mater. Chem. A 2020. 
216. López-Covarrubias, J. G.; Soto-Muñoz, L.; Iglesias, A. L.; VillarrealGómez, L. J.; Materials (Basel) 2019, 12, 3190.

217. Kaschuk, J. J.; Miettunen, K.; Borghei, M.; Frollini, E.; Rojas, O. J.; Cellulose 2019, 26, 6151 .

218. Jayaraman, S.; Aravindan, V.; Suresh Kumar, P.; Chui Ling, W.; Ramakrishna, S.; Madhavi, S.; ACS Appl. Mater. Interfaces 2014, 6, 8660.

219. Li, Q.; Guo, J.; Xu, D.; Guo, J.; Ou, X.; Hu, Y.; Qi, H.; Yan, F.; Small 2018, 14, 1704203.

220. Zhao, Q.; Xie, H.; Ning, H.; Liu, J.; Zhang, H.; Wang, L.; Wang, X.; Zhu, Y.; Li, S.; Wu, M.; J. Alloys Compd. 2018, 737, 330.

221. Raulo, A.; Bandyopadhyay, S.; Ahamad, S.; Gupta, A.; Srivastava, R.; Formanek, P.; Nandan, B.; J. Power Sources 2019, 431, 250.

222. Smith, S. A.; Park, J. H.; Williams, B. P.; Joo, Y. L.; J. Mater. Sci. 2017, $52,3657$.

223. Shayapat, J.; Chung, O. H.; Park, J. S.; Electrochim. Acta 2015, 170, 110.

224. Miao, F.; Shao, C.; Li, X.; Lu, N.; Wang, K.; Zhang, X.; Liu, Y.; Energy 2016, 95, 233.

225. Li, X.; Zhao, Y.; Bai, Y.; Zhao, X.; Wang, R.; Huang, Y.; Liang, Q.; Huang, Z.; Electrochim. Acta 2017, 230, 445.

226. Agyemang, F. O.; Tomboc, G. M.; Kwofie, S.; Kim, H.; Electrochim. Acta 2018, 259, 1110.
227. Ren, J.; Musyoka, N. M.; Annamalai, P.; Langmi, H. W.; North, B. C.; Mathe, M.; Int. J. Hydrogen Energy 2015, 40, 9382.

228. Dissanayake, M. A. K. L.; Sarangika, H. N. M.; Senadeera, G. K. R.; Divarathna, H. K. D. W. M. N. R.; Ekanayake, E. M. P. C.; J. Appl. Electrochem. 2017, 47, 1239.

229. Li, L.; Xiao, J.; Sui, H.; Yang, X.; Zhang, W.; Li, X.; Hagfeldt, A.; Wu, M.; J. Power Sources 2016, 326, 6.

230. Cheng, F.; Ou, Y.; Liu, G.; Zhao, L.; Dong, B.; Wang, S.; Wen, S.; Nanomaterials 2019, 9, 783.

231. Persano, L.; Camposeo, A.; Tekmen, C.; Pisignano, D.; Macromol. Mater. Eng. 2013, 298, 504.

232. Akampumuza, O.; Gao, H.; Zhang, H.; Wu, D.; Qin, X.-H.; Macromol. Mater. Eng. 2018, 303, 1700269.

233. Liang, F. C.; Kuo, C. C.; Chen, B. Y.; Cho, C. J.; Hung, C. C.; Chen, W. C.; Borsali, R.; ACS Appl. Mater. Interfaces 2017, 9, 16381.

234. Luo, C. J.; Stoyanov, S. D.; Stride, E.; Pelan, E.; Edirisinghe, M.; Chem. Soc. Rev. 2012, 41, 4708.

235. Song, J.; Kim, M.; Lee, H.; Polymers (Basel) 2020, 12, 1386.

236. Vass, P.; Szabó, E.; Domokos, A.; Hirsch, E.; Galata, D.; Farkas, B.; Démuth, B.; Andersen, S. K.; Vigh, T.; Verreck, G.; Marosi, G.; Nagy, Z. K.; WIREs Nanomedicine and Nanobiotechnology 2020, 12, 1. 